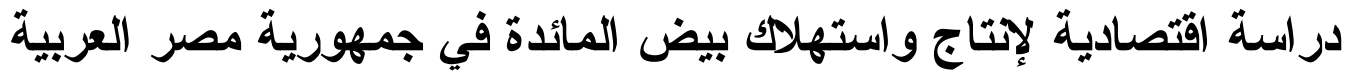
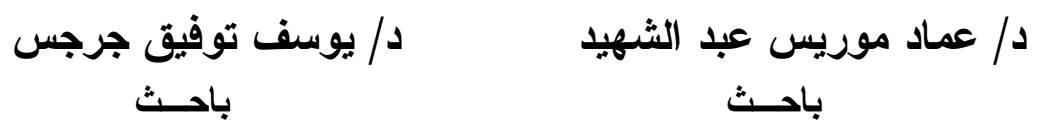

أ.د/ طلعت رزق الله النقادي

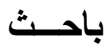

أستاذ الاقتصاد الزراعي المتفرغ الهادي

معهز بحوث الاقتصاد الزراعي - مركز البحوث الزراعية

مقدمة:

يعد القطاع الزر اعي المصري من أهم القطاعات الاقتصادية المصرية وأهم القطاعات الإنتاجية التي

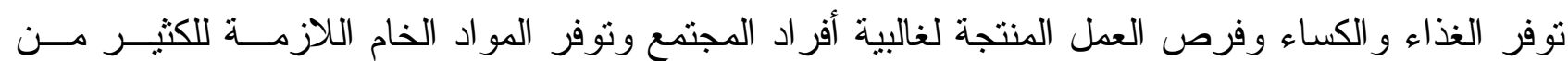
الصناعات المحلية المصرية وتوفير متطلبات القطاعات الاقتصادية الأخر .

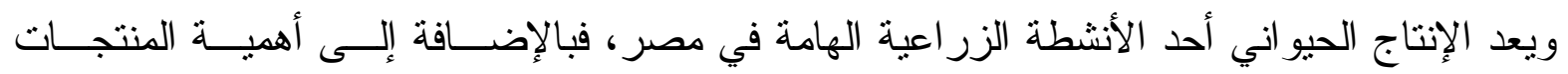

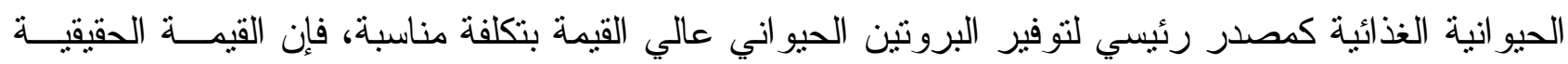

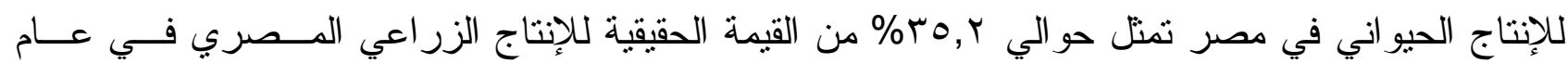

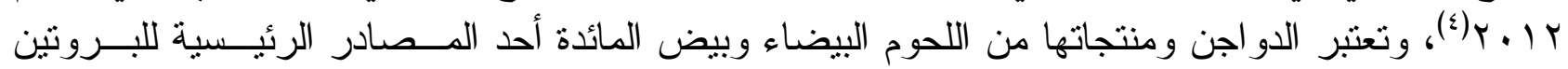

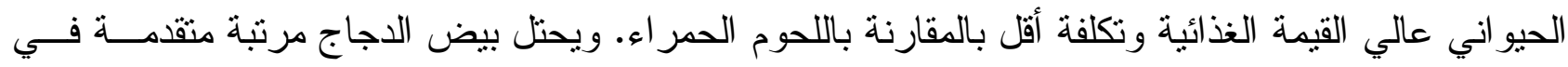
مجموعة البروتينات الحيو انية، و لا تقتصر أهميته الاقتصادية على مقدار ما يساهم به في الاخل من الإنتـاج

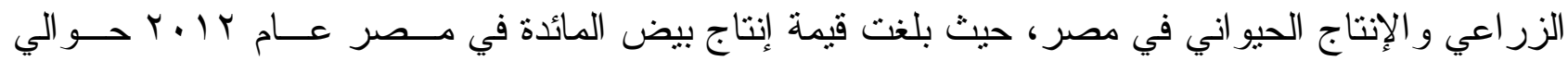

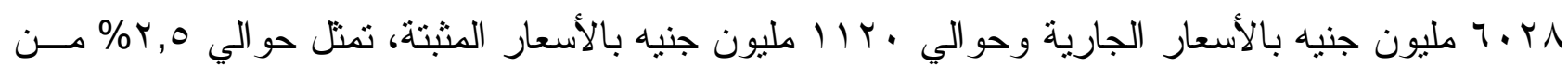

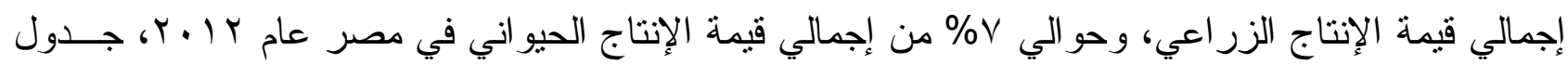

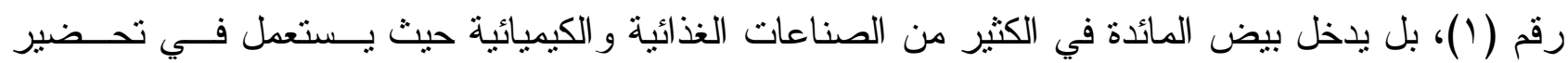

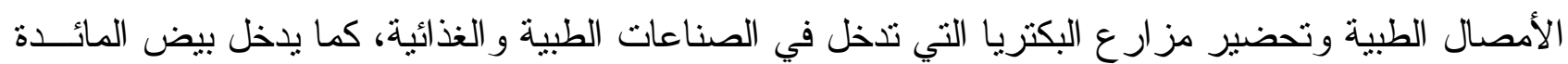

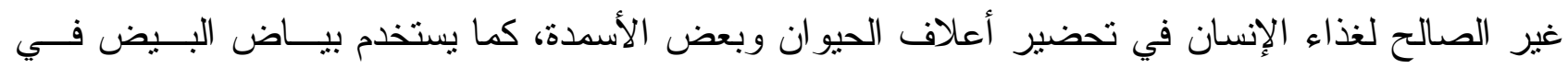

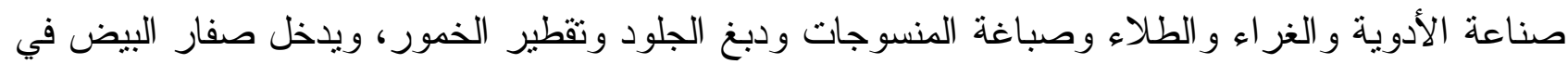

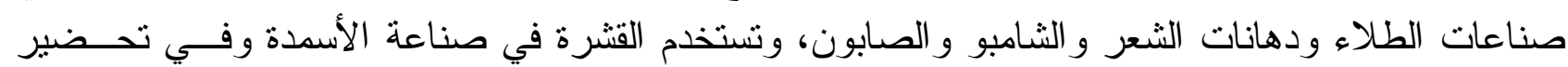
مخاليط الأملاح المعدنية. وتعتبر جمهورية مصر العربية مكتقية ذاتياً بالنسبة لبيض المائدة حيث يتعادل الإنتاج المحلـي مسنـ بيض المائدة مع الاستهلاك المحلي منه، و لا توجد و اردات من بيض المائدة سوى بعض الكميــات الـضئيلة

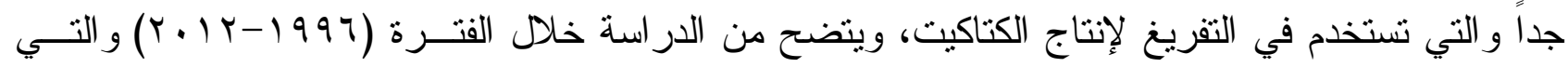
تمثل الفترة بعد تطبيق سياسات التحرر الاقتصادي في مصر، جدول رقم (ب)، أن الإنتاج المحلي المــصري

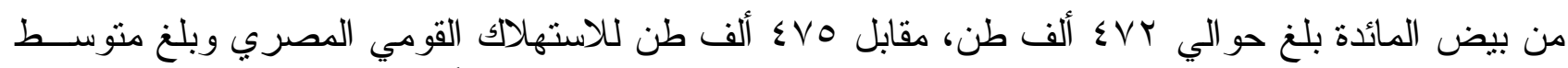

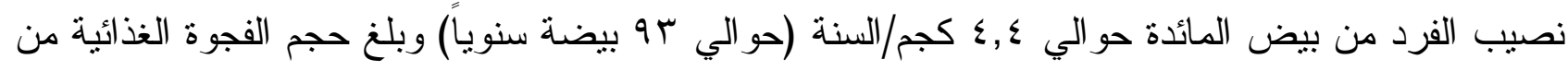

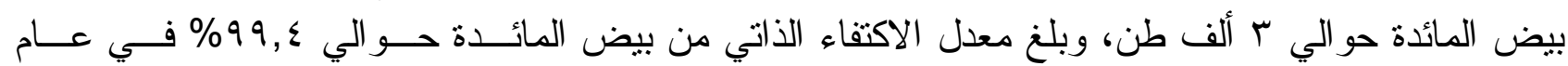
.$T \cdot 1 Y$

مشكلة البحث : م: م: م:

تتمنل مشكلة الدر اسة في أنه على الرغم من زيادة الإنتاج المحلي من بيض المائدة في مصر خــاله

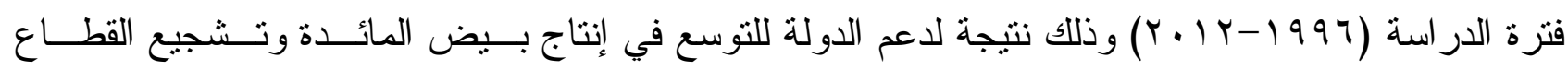

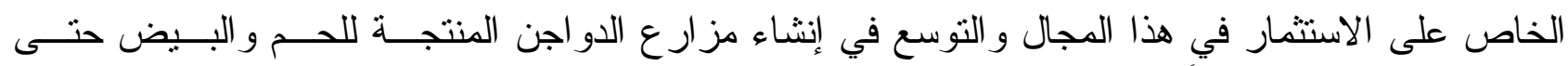

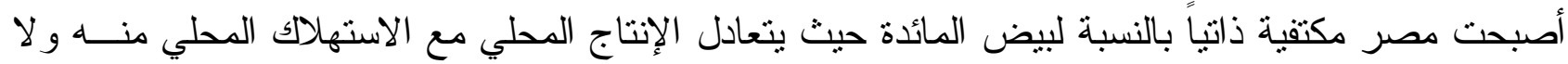

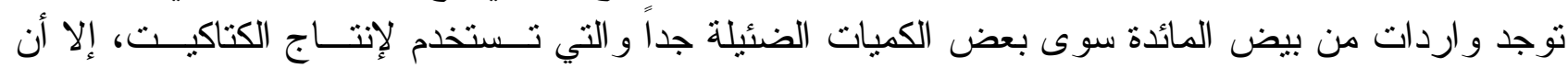


الزيادة المستمرة و المضطردة في عدد السكان وتحسن الاخول الفردية وزيادة الطلب علــى بــيض المائــدة

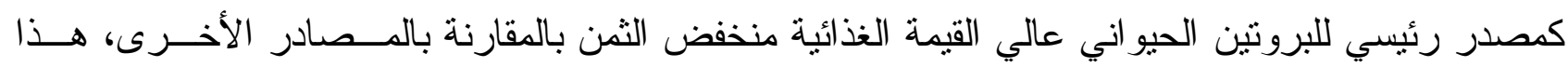
بالإضافة إلى تطبيق سياسات التحرر الاقتصادي وما ترتب عليها من إطلاق قوى السوق و المنافسة وتحريــر

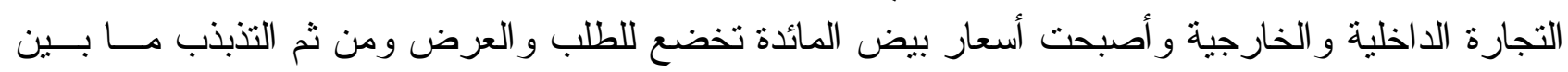

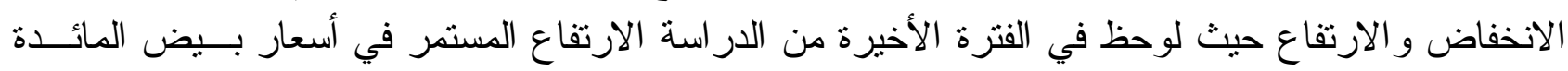

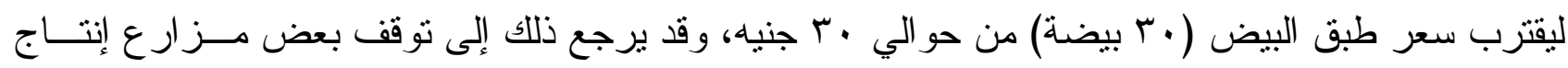

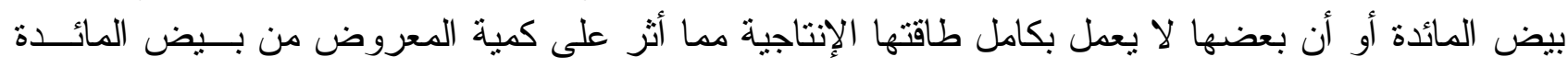
و الارتفاع المستمر في أسعاره المحلية. هدف الار اسة :

استهدفت الدر اسة إلقاء الضوء على تطور الإنتاج المحلي من بيض المائدة و التجارة الخارجية لله من

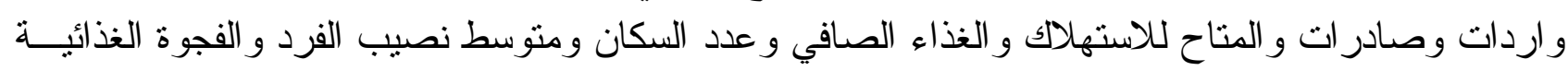

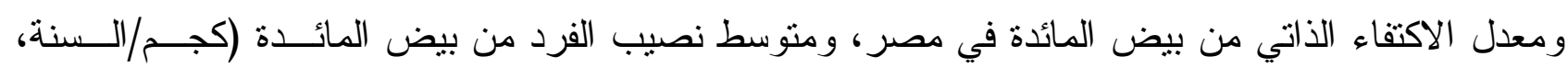

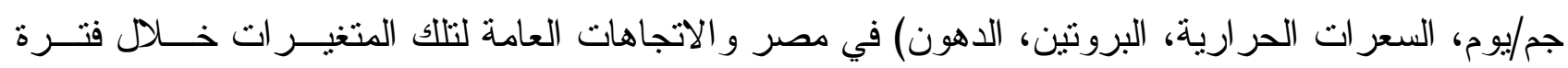

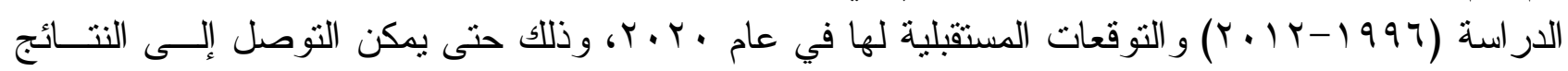
و التوصيات التي يمكن أن تساهم بدور فعال في رسم السياسات الإنتاجية الحيو انية و التي من شأنها أن تــؤدي أندي

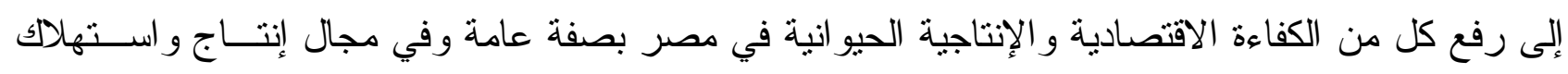

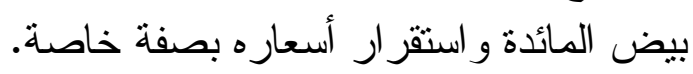
الطريقة البحثية ومصادر البيانات :

لتحقيق الأهداف المشار إليها فقد تم استخدام منهجي التحليل الإحصائي الوصفي و الكمي و الأســلوب ألوب

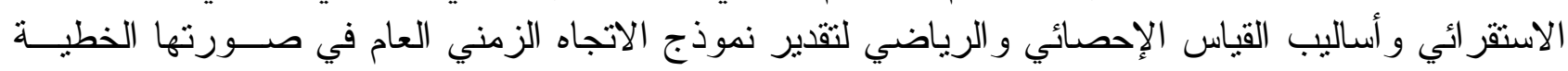

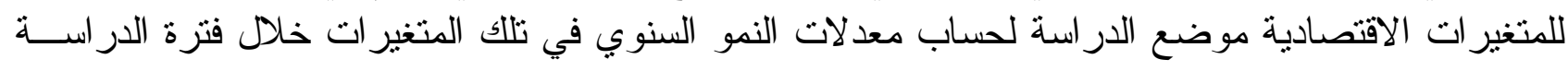

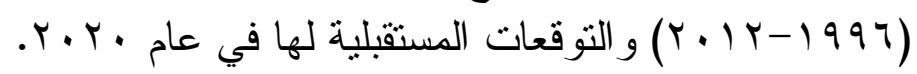

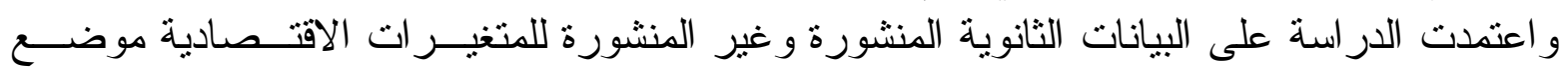

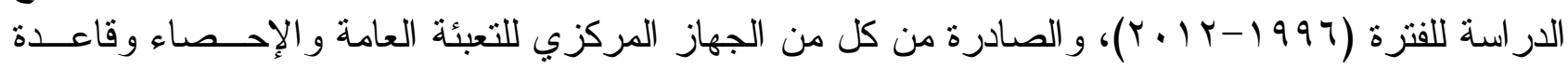

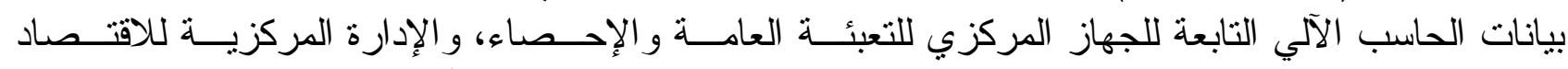

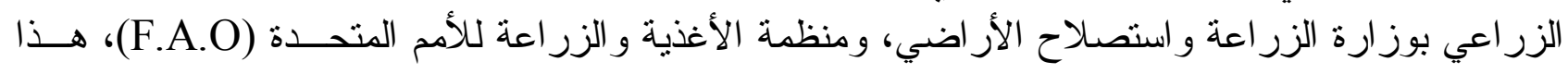

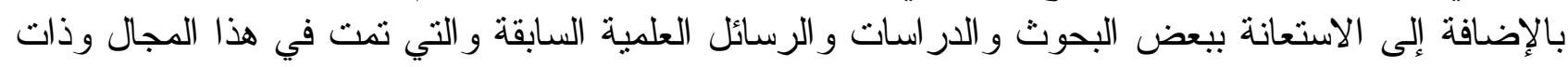

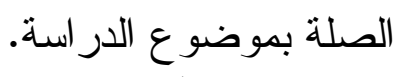
النتائج البحثية: أولاًِ- تطور القيمة الحقيقية للإِتاج الزراعي والإتتاج الحيواني وإنتاج بيض المائدة في مصر :

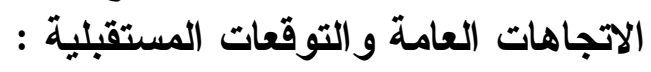

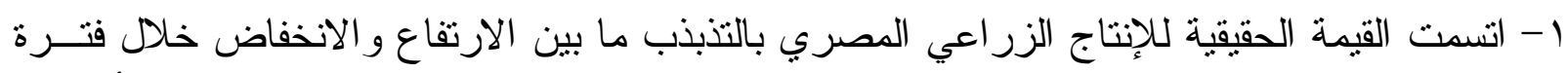

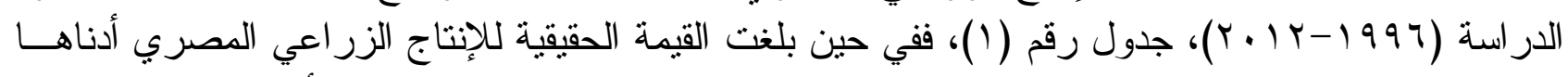

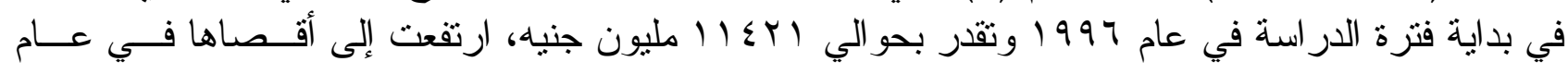

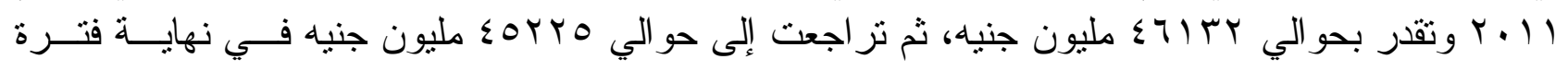

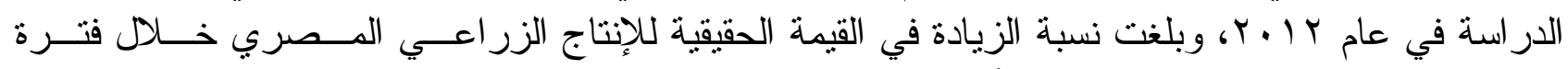

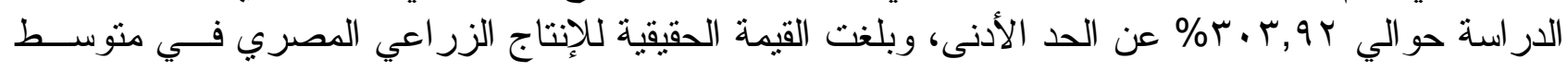

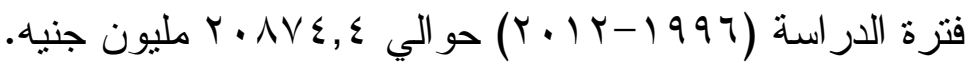




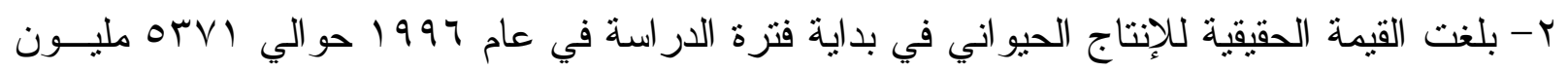

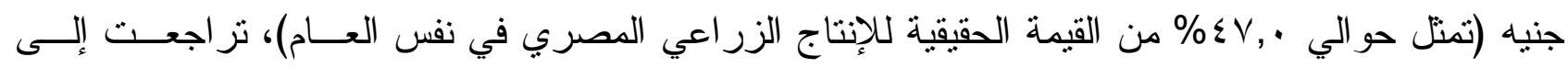

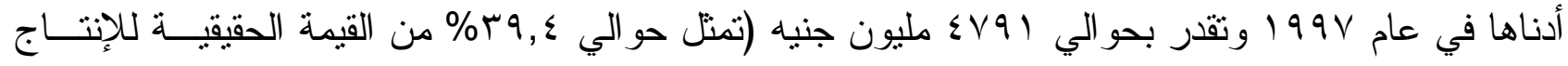

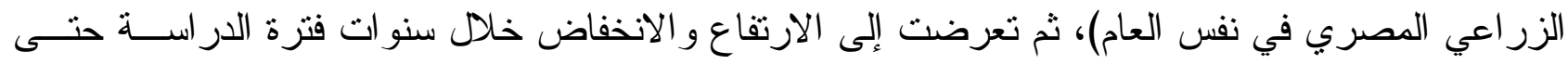

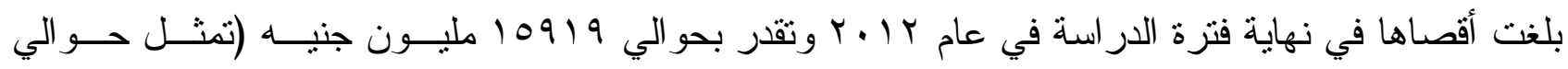
r r r \% من القيمة الحقيقية للإنتاج الزر اعي المصري في نفس العام)، وبلغت نسبة الزيادة في القيمة الحقيقية

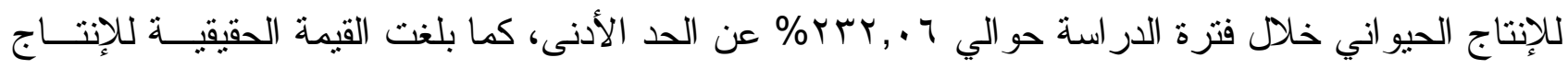

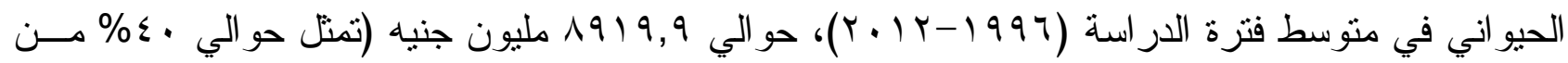
القيمة الحقيقية للإنتاج الزر اعي في منوسط نفس الفترة لفرة)

جدول رقم (1): تطور قيمة الإتتاج الزراعي وقيمة الإتتاج الحيواني وقيمة إنتاج بيض المائدة في مصر

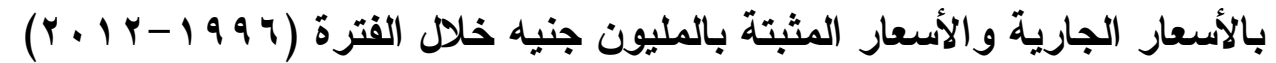

\begin{tabular}{|c|c|c|c|c|c|c|c|c|c|}
\hline \multicolumn{4}{|c|}{ فَيمة إنتاج بيض المائدة } & \multicolumn{3}{|c|}{ فيمة الإتتاج الحيواني } & \multicolumn{2}{|c|}{ فيمة الإتتاج الزراعي } & \multirow{2}{*}{ السنوات البيان } \\
\hline للحيو اني & $\begin{array}{c}\% \\
\text { للزر اعي }\end{array}$ & مثبتة * & جارية & $\begin{array}{c}\% \\
\text { للزراعي }\end{array}$ & مثبتة * م & جارية & مثبتة * مثن & جارية & \\
\hline$r, 7$ & $1, \mathrm{~V}$ & 194 & $V .0$ & $\varepsilon \vee$, & OrVI & 19790 & 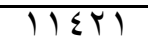 & हाATY & 1997 \\
\hline$\varepsilon, 9$ & 1,9 & THE & ᄉฯ & $r q, \varepsilon$ & $\varepsilon \vee q \varepsilon$ & $\mid V \wedge 10$ & 14109 & $\leqslant 011 K$ & $199 \mathrm{~V}$ \\
\hline$\varepsilon, V$ & 1,1 & TMT & Avq & ऍ , 7 & $\leqslant 99$. & $|\wedge \wedge \vee|$ & K Yq4q & 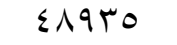 & 1991 \\
\hline$r, \Lambda$ & 1,1 & $r \leqslant 9$ & 909 & $\varepsilon \vee, 1$ & $T \leq 7 V$ & $r \leqslant \wedge 9$. & ITV. & OYA $\leq 0$ & 1999 \\
\hline$r, v$ & 1,1 & Y74 & $1 . Y \Lambda$ & $\varepsilon \wedge, 9$ & V) $9 \leqslant$ & TVAIT & $1 \leqslant V \cdot A$ & $07 \wedge 71$ & $r \ldots$ \\
\hline$\varepsilon, 0$ & $r, r$ & TYA & $1 \Gamma \leqslant V$ & $\varepsilon q, r$ & VTr. & ז... & $1 \leqslant \wedge 7$. & 7.900 & $r \ldots 1$ \\
\hline $0, \varepsilon$ & $r,$. & $\varepsilon \leqslant 9$ & $194 \pi$ & 07, . & NTr人 & TOV $\leqslant \varepsilon$ & $1 \leqslant \wedge \wedge \vee$ & THAYY & $r \ldots r$ \\
\hline$\varepsilon, V$ & $r,$. & ¿1^ & $r \cdot V \wedge$ & $T \varepsilon,$. & (9). & ह & $1 T 91 \mathrm{~V}$ & 79Yor & $r \ldots r$ \\
\hline$\varepsilon, 7$ & $r, \Lambda$ & $\varepsilon r V$ & $r \mid \leqslant r$ & $\pi, 1$ & 9417 & $\varepsilon 7 \vee \mu q$ & $10 \ldots V$ & Vorql & $r \ldots \varepsilon$ \\
\hline$\varepsilon, r$ & 1,7 & rVt & $r \cdot \varepsilon r$ & $r V, r$ & (4Tו & $\varepsilon V Y \leq T$ & NTH & $\mid$ TrqVI & r... \\
\hline 0,7 & $r,$. & $\leqslant 79$ & rVAO & r, & ס & $\leqslant 9719$ & סזוTץ & $1 \pi v \leqslant 19$ & $r \ldots q$ \\
\hline 0,7 & $r, \cdot$ & $\varepsilon r \tau$ & $r \cdot \wedge q$ & $\Gamma_{0, \varepsilon}$ & VATK & 00YT. & $r 101 \pi$ & $1009 \leqslant 0$ & $r \ldots v$ \\
\hline $7, \Lambda$ & $r, \Sigma$ & Tro & $\varepsilon \varepsilon 19$ & ro,. & $919 V$ & 70.7. & YTY & 110777 & $r \ldots \Lambda$ \\
\hline $0, \mathrm{~V}$ & $r, 1$ & $0 \wedge V$ & r900 & r, & $1 . r O V$ & $791 \%$. & रی川 & $1 \wedge 9 \leqslant r \wedge$ & $r \ldots q$ \\
\hline $7, r$ & $r, r$ & NTO & $\{107$ & $r v,$. & ITr.V & VVTAY & r...r & r.9T0 & $r \cdot 1$. \\
\hline 0,9 & $r_{,} \cdot$ & $9 Y 7$ & $0 . r$. & qT, & 107Y & $1 \leqslant 779$ & $\sum T \mid M T$ & $r \leqslant 99 \wedge 9$ & $r .11$ \\
\hline $\mathrm{v}$, . & $r, 0$ & Wr. & $T . Y \wedge$ & $r 0, r$ & 10919 & 10771 & SOYYO & rETrOT & $r .1 r$ \\
\hline 0,1 & $T, T$ & $\varepsilon \vee 9, \wedge$ & T090,0 & $\xi \cdot, \cdot$ & 1919,9 & $\varepsilon V \cdot T Y$ & T.AV乏, & $\prod \wedge \varepsilon \mid \vee, \Lambda$ & آلمتوسط العام \\
\hline
\end{tabular}

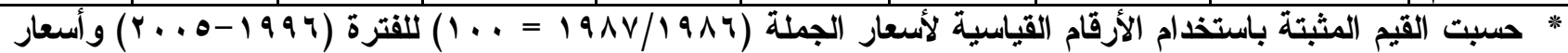

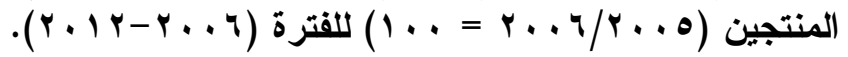

المصدر : جمعت وحسبت من :

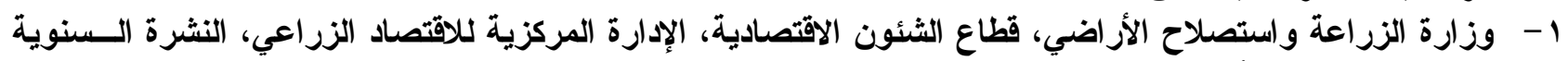

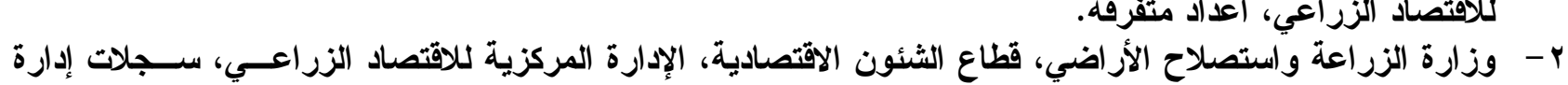
الإحصاءات الزراعية، بيانات غير الأهي، منشورة.

r- اتسمت القيمة الحقيقية لإنتاج بيض المائدة في مصر بالتذبذب ما بين الارتفاع و الانخفاض خــاضلال

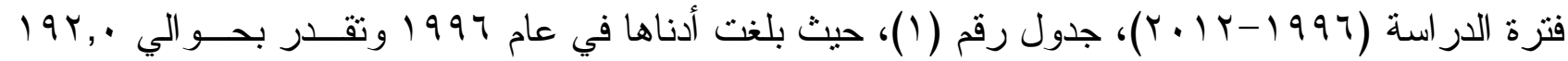

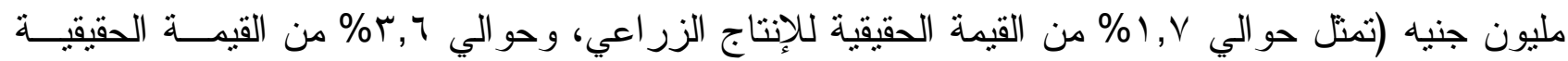

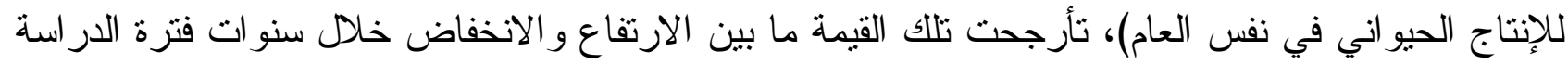

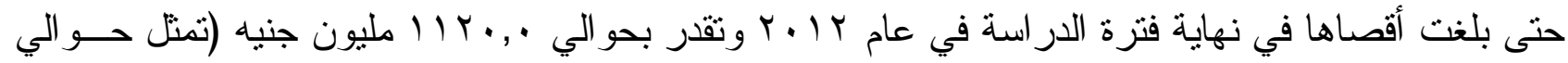

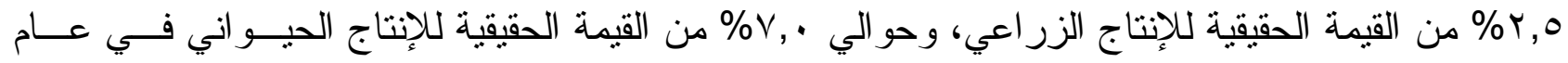

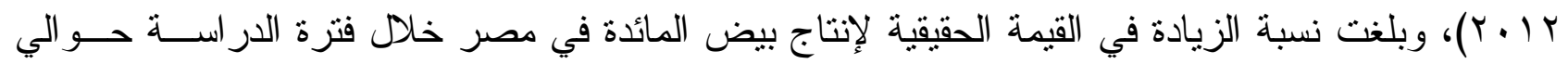




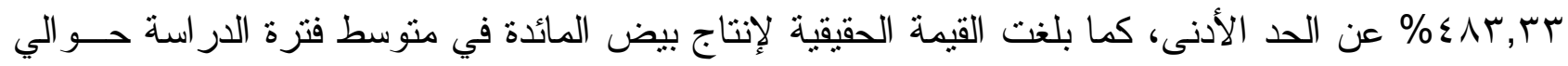

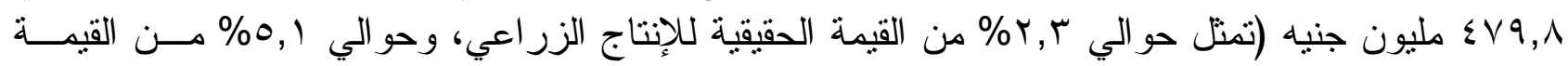

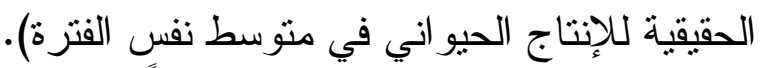

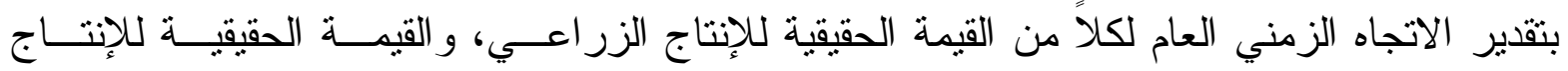

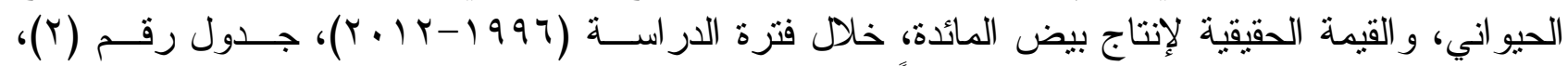

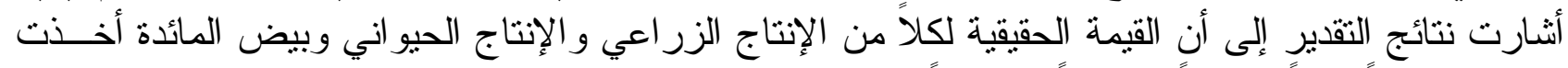

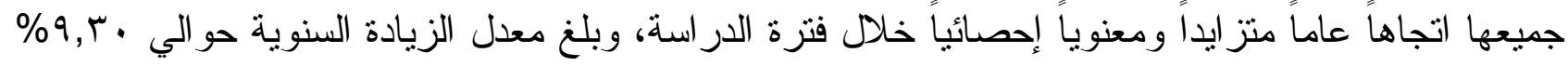

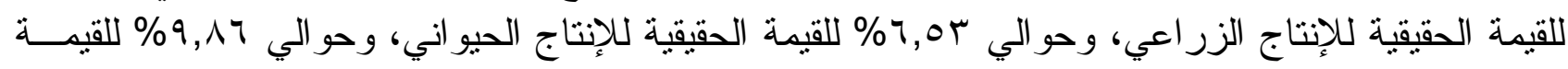

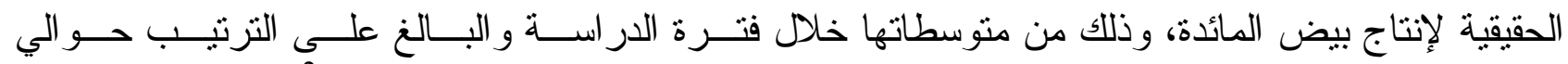

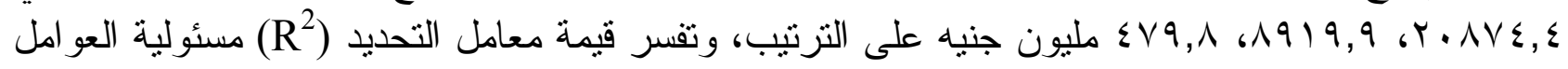

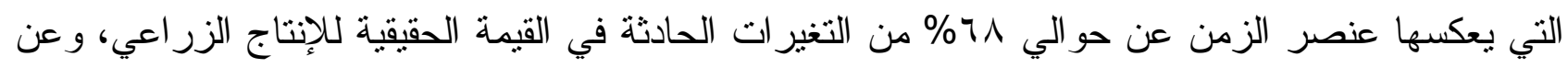

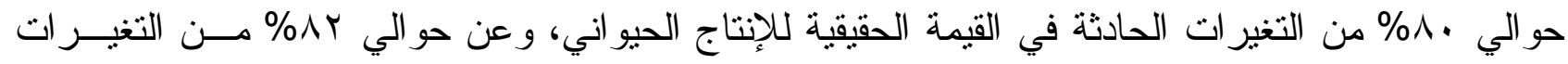

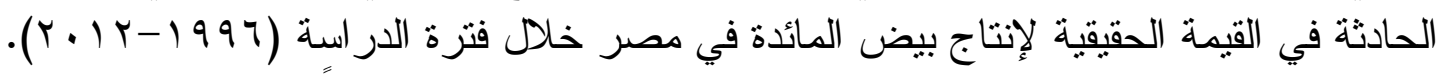

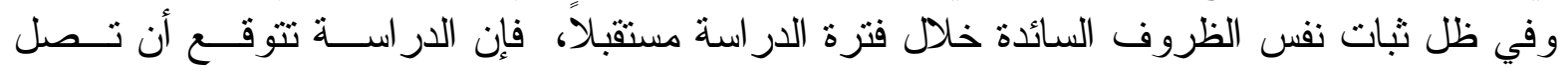

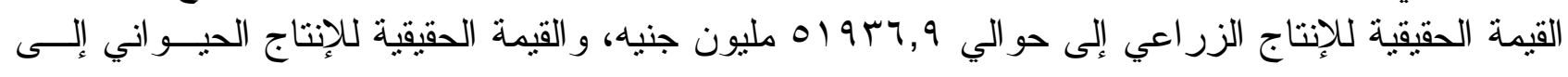

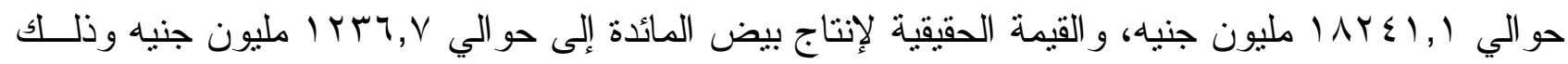

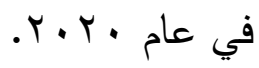
جدول رقم (ץ): الاتجاه الزمني العام لقيمة الإتتاج الزراعي وقيمة الإنتاج الحيواني وقيمة إنتاج البيض في مصر بالمليون جنيه بالأسعار الجارية والمثبتة في القترة (

\begin{tabular}{|c|c|c|c|c|c|c|c|c|}
\hline 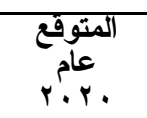 & معدل & 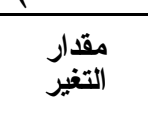 & الظتوسطة & التحليد & F المقارة & معادلة الاتجاه الزمني العام & المتغيرات & s \\
\hline$\Gamma \leqslant|\wedge| .$, & 11,199 & 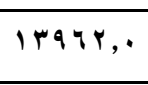 & $\| \wedge \leqslant \mid v, \wedge$ & $\cdot, 911$ & *** or,or. & 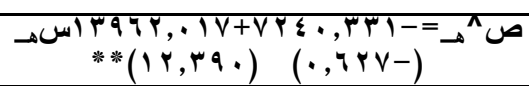 & الزراعي ألجارية & \\
\hline 01949,9 & $9, \Gamma$. & $19 \leqslant 1, \varepsilon$ & $Y \cdot \wedge \vee \varepsilon, \varepsilon$ & צ & raA & 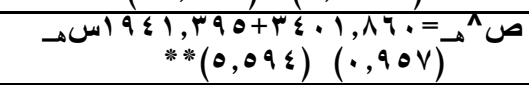 & 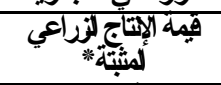 & \\
\hline T11104 & $9,0$. & $\leqslant \leqslant ४ \wedge, q$ & $\leqslant v \cdot 71, q$ & $\cdot 9 \times 1$ & $* * \because q \vee, r Y$. & 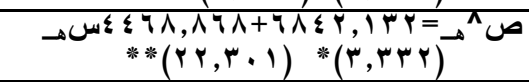 & 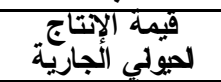 & \\
\hline $\mid A r \leqslant 1,1$ & Y,OT & OAY,T & 1919,9 & $\cdot, \mathrm{\vee} 90$ & $* * \Delta \wedge, r, q$ & 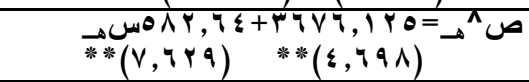 & 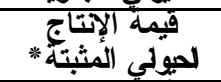 & $\varepsilon$ \\
\hline VVYI,0 & $I r, r v$ & & $r \otimes q 0,0$ & , ,QYा & 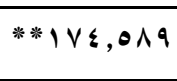 & 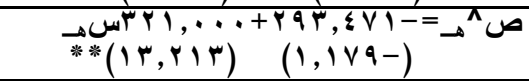 & فيمة أنَأتاجية ألبيض & \\
\hline Irrq,V & $9, \wedge 4$ & $\leqslant V, r \cdot q$ & $\leqslant \vee q, \Lambda$ & $\cdot, \wedge 1 \wedge$ & **ฯ V, rV D & 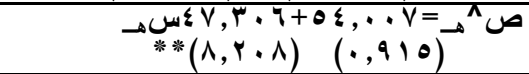 & 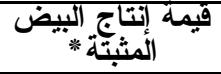 & \\
\hline
\end{tabular}

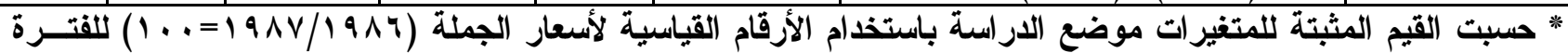

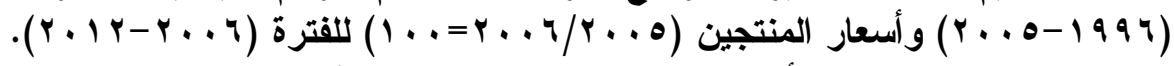

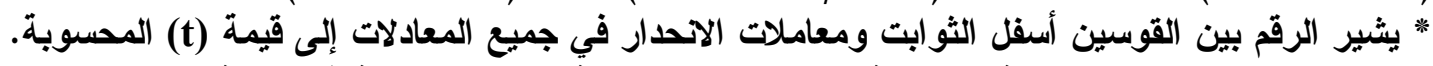

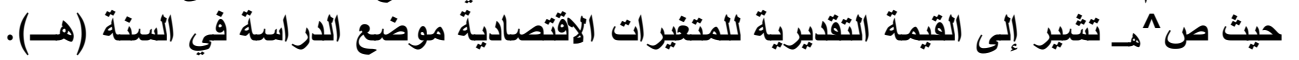

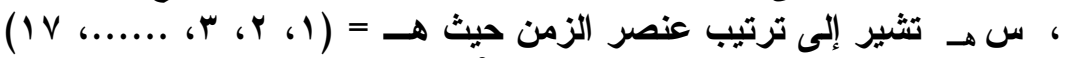

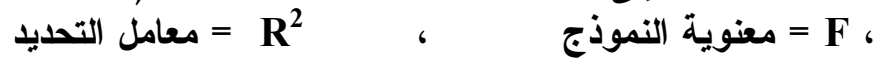

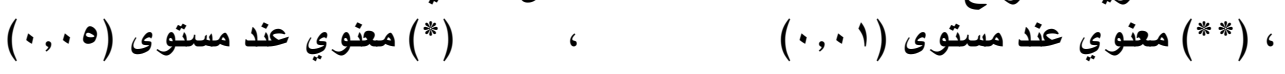

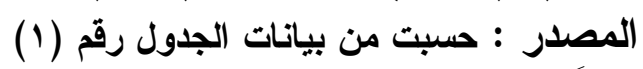

ثانياً- تطور المؤشر ات الإتتاجية والاقتصادية لبيض المائدة - الاتجاهات العامة والتوقعات المستقبلية :

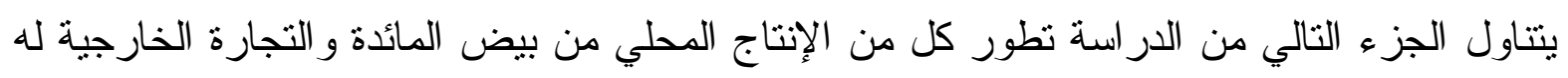

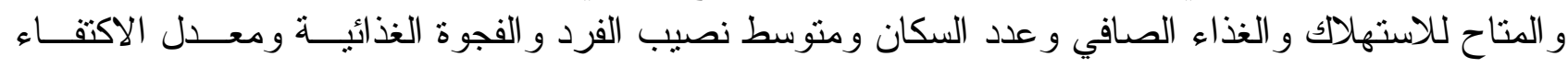

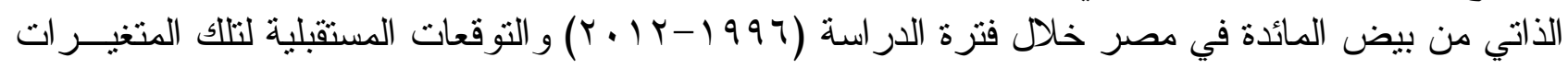

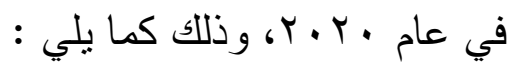


ا - تطور الإتتاج المحلي من بيض المائدة في مصر - الاتجاهات العامة والتوقعات المستقبلية :

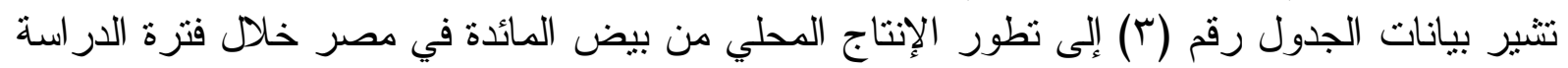

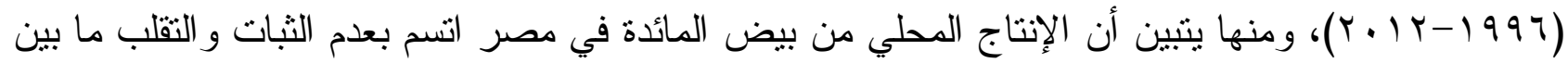

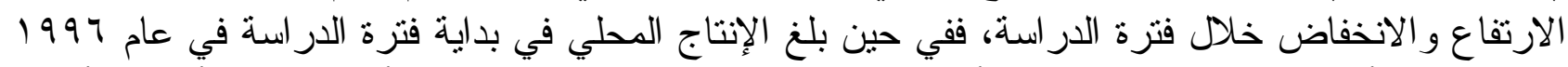

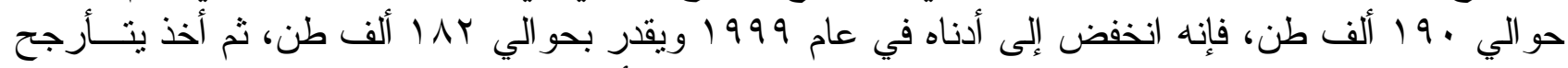

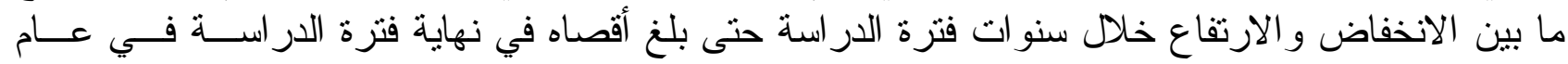

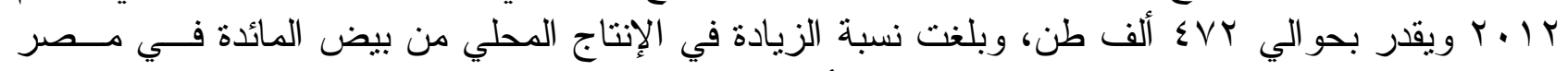

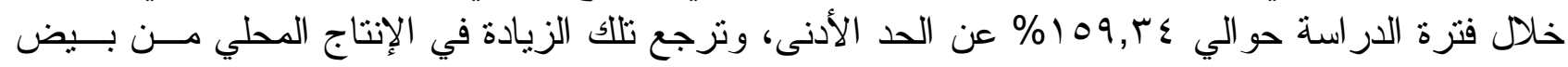

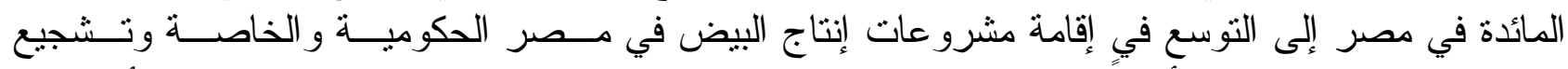

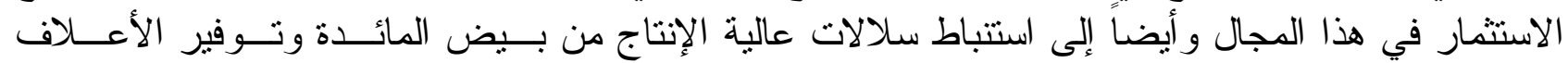

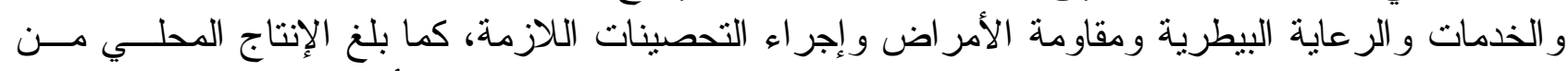

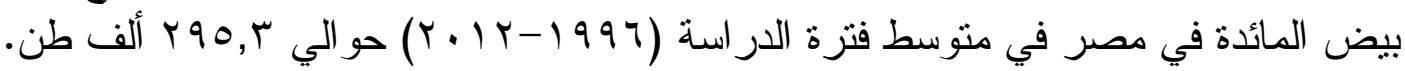

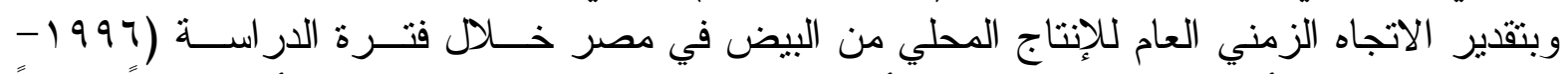

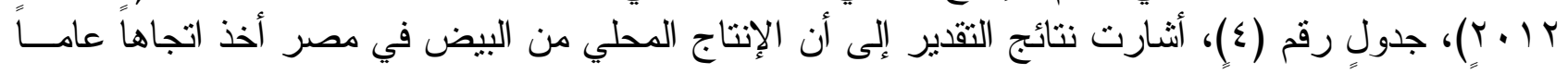

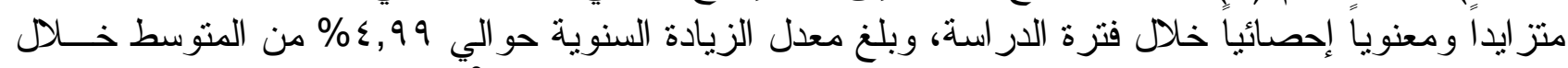

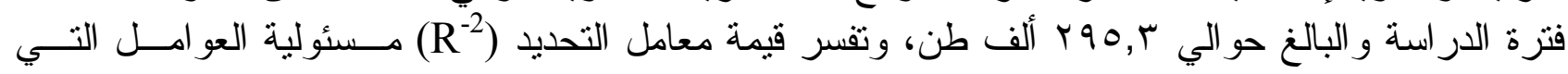

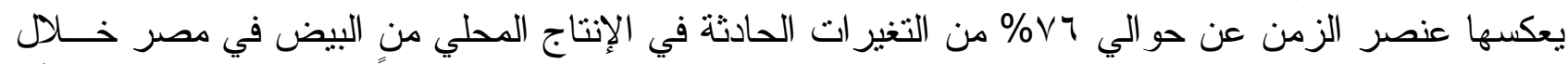

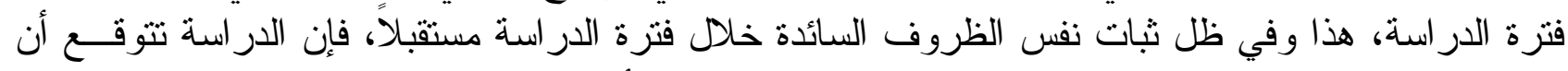

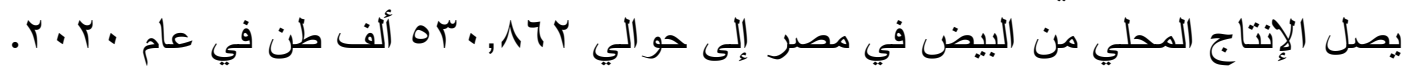

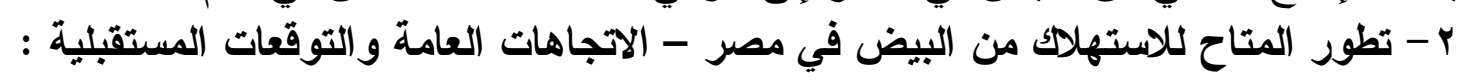

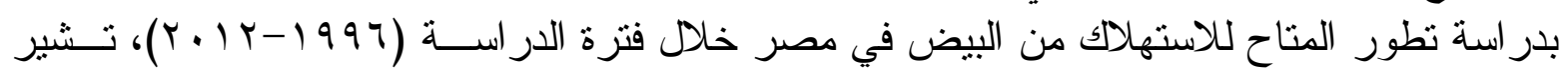

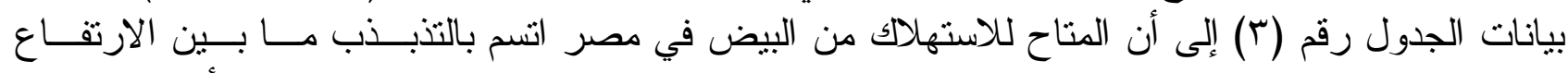

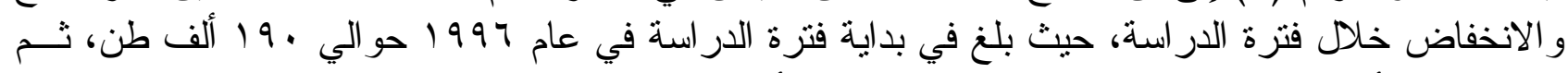

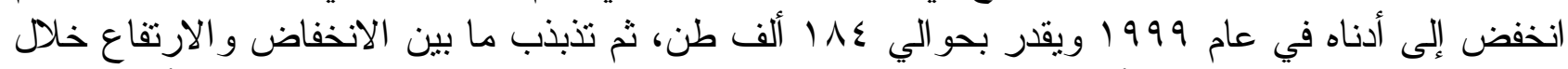

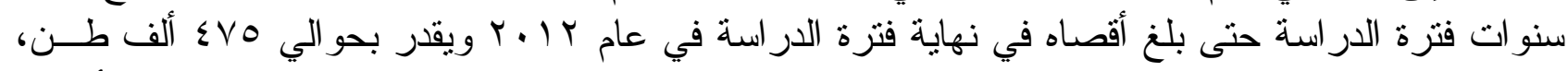

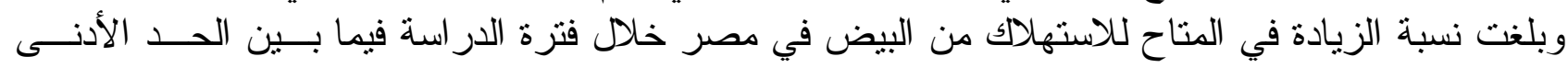

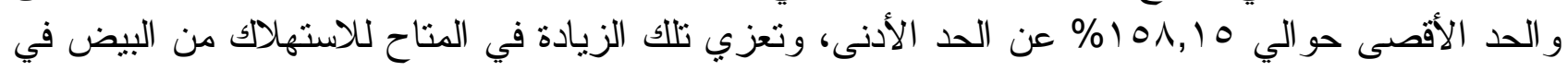

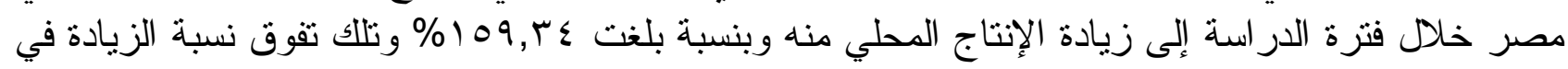

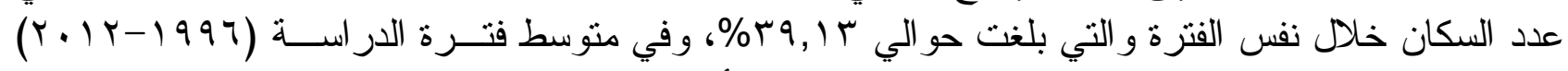

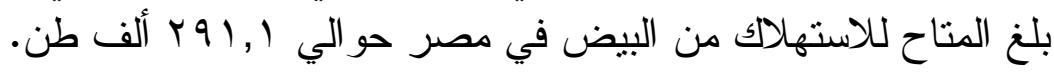

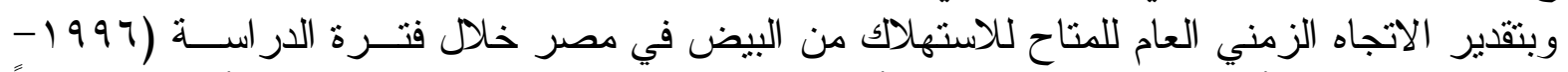

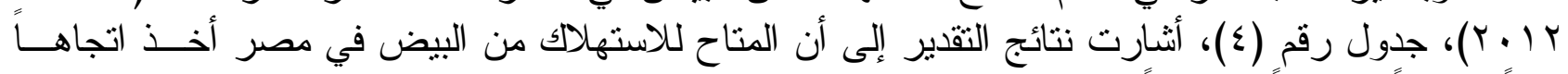

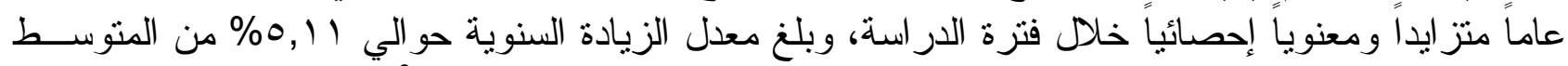

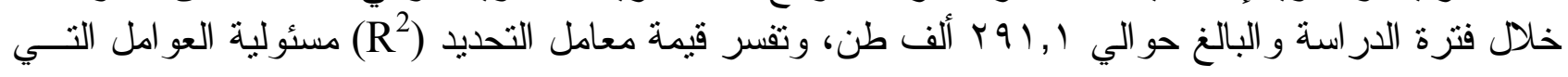

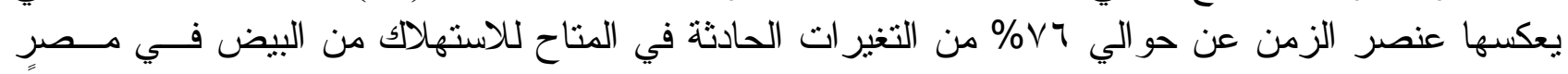

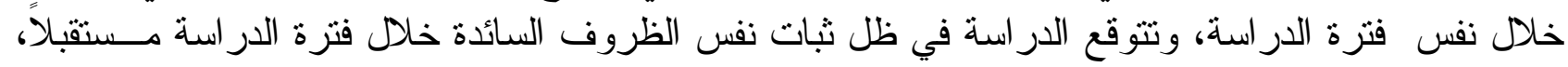

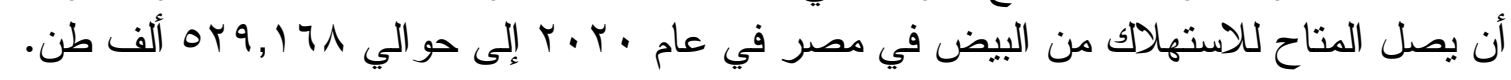

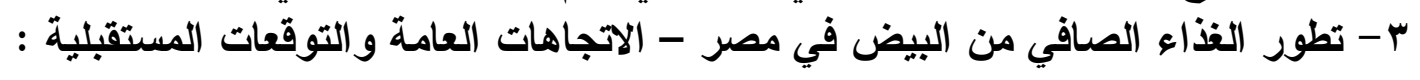

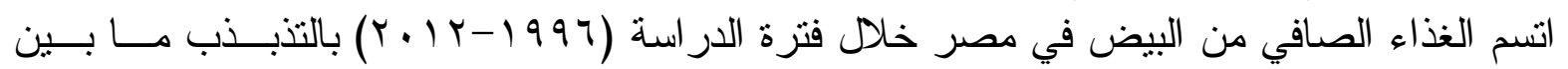

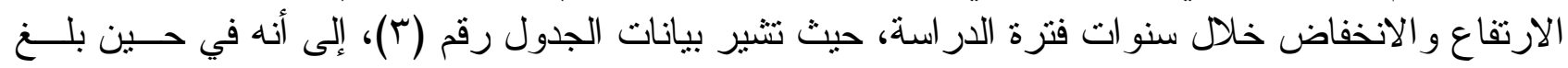




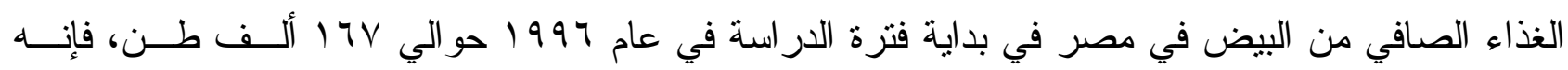

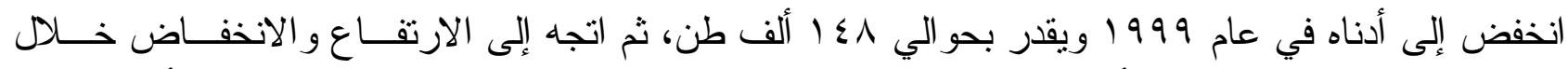

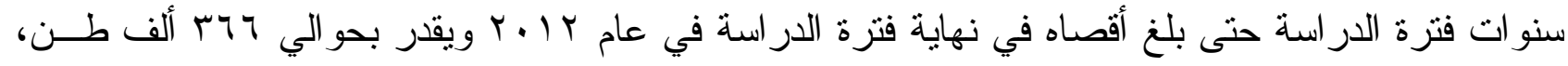

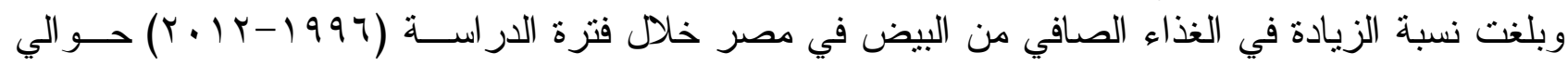

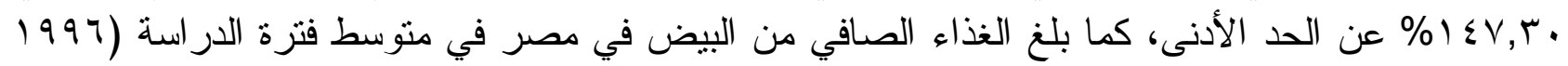

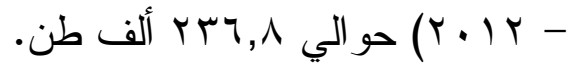

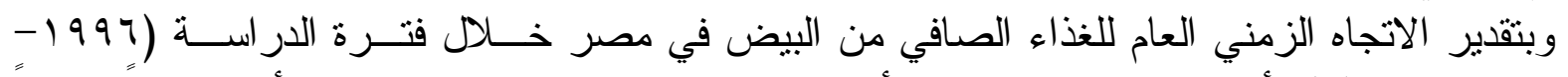

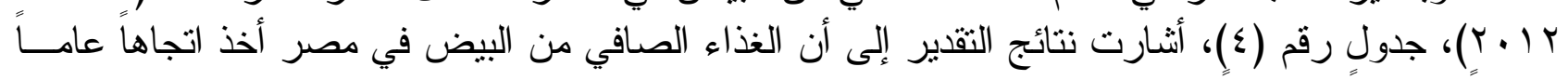

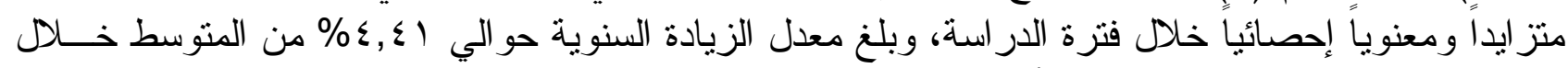

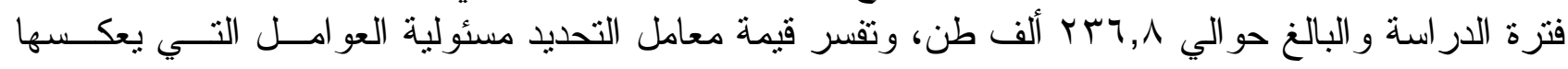

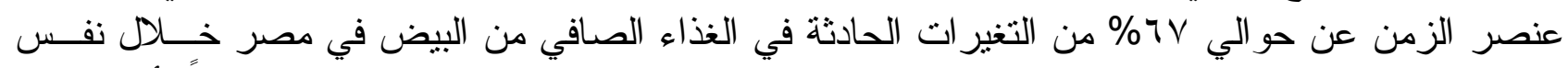

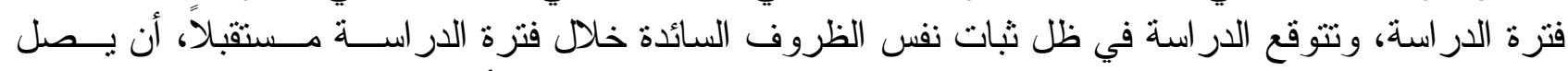

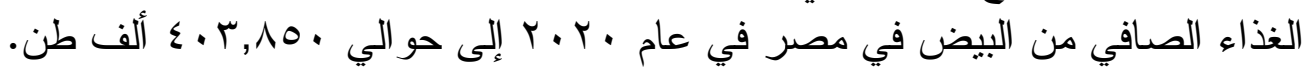

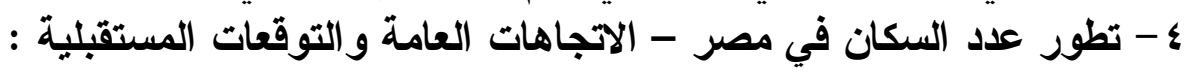

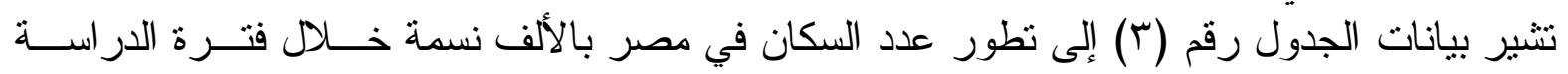

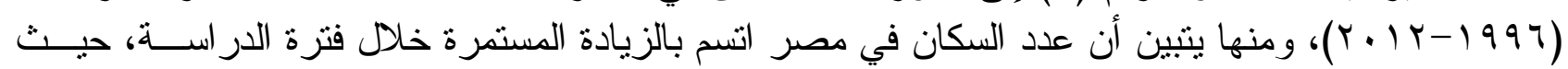

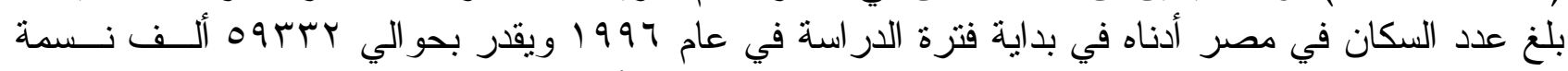

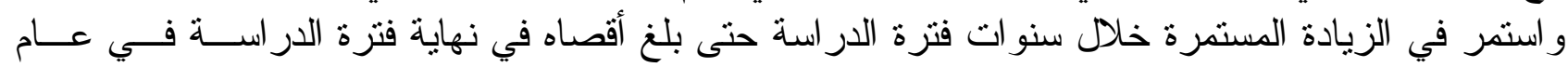

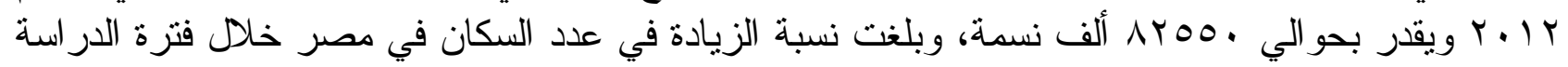

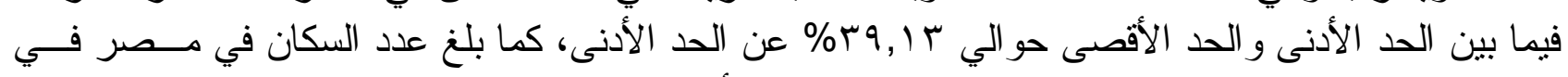

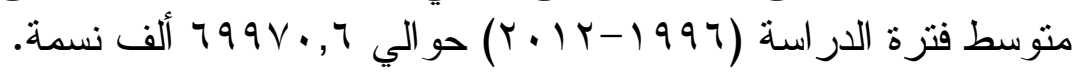

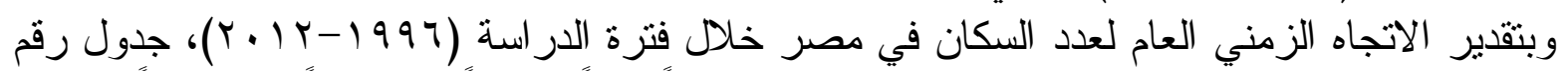

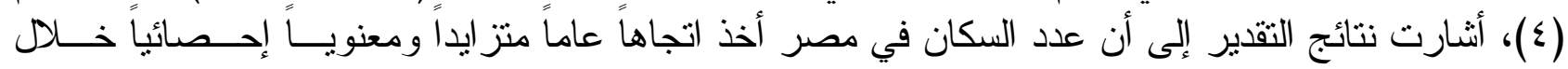

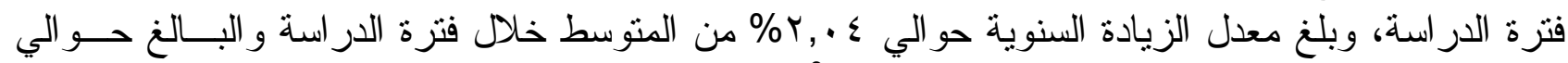

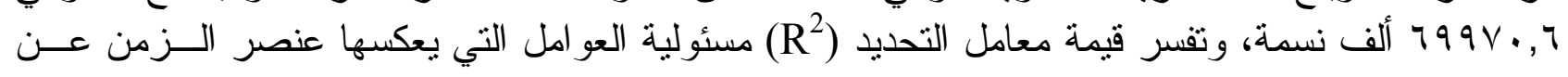

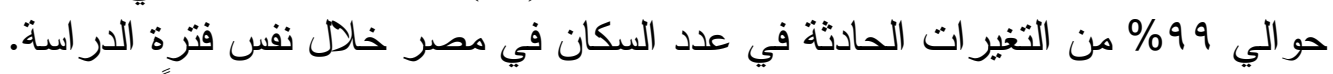

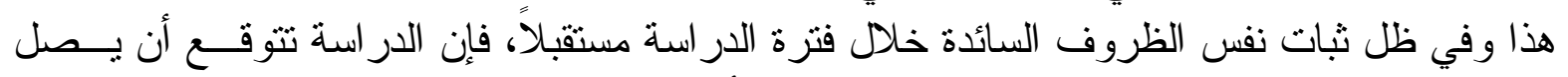

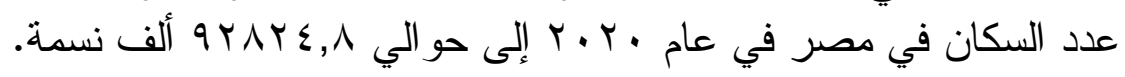

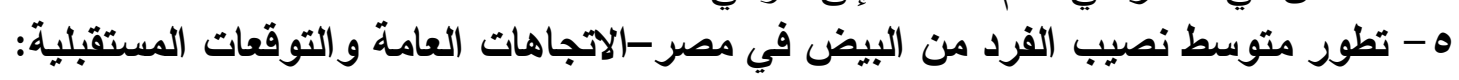

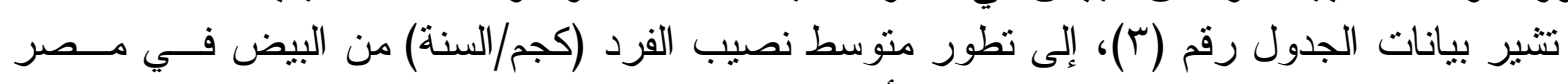

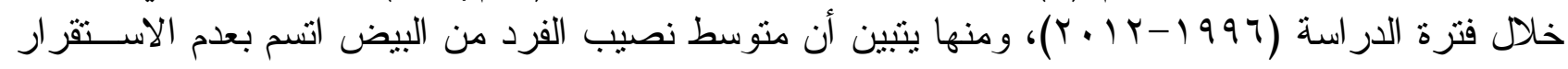

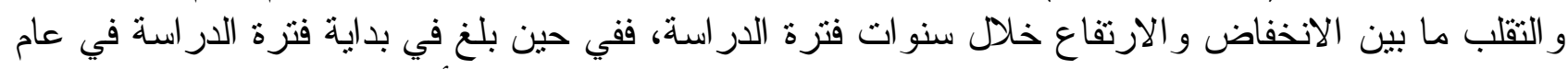

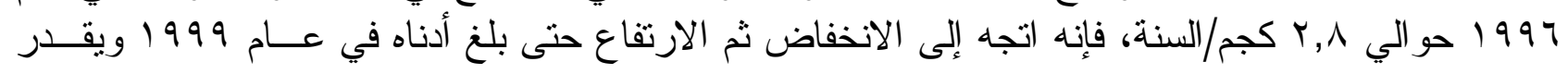

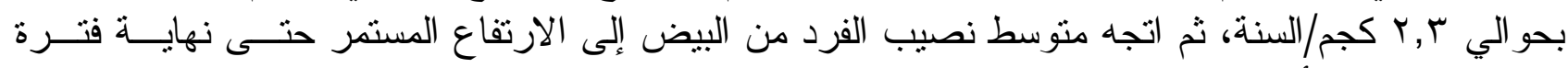

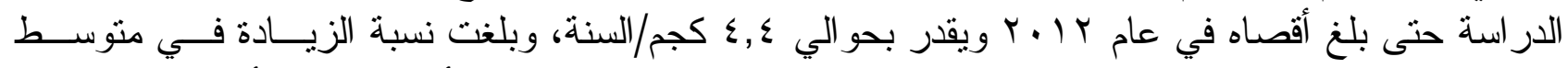

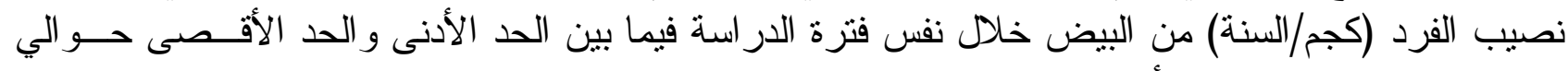

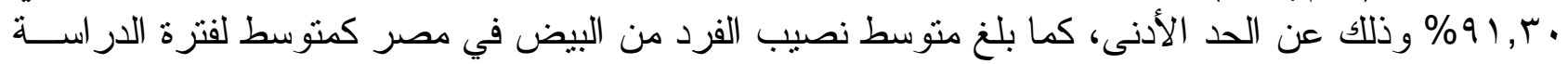

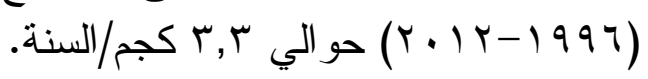

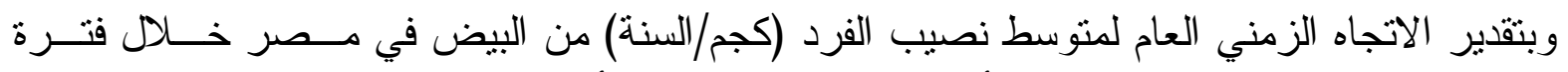

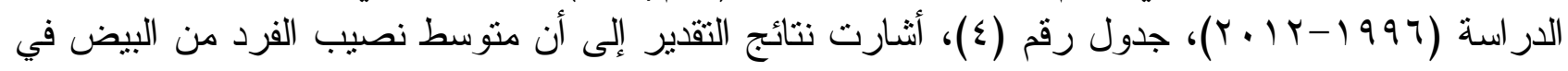




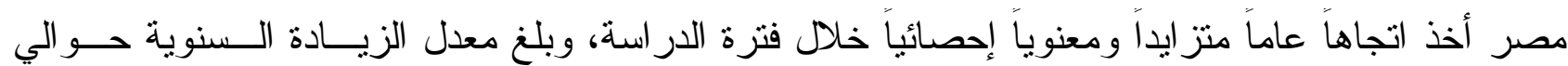

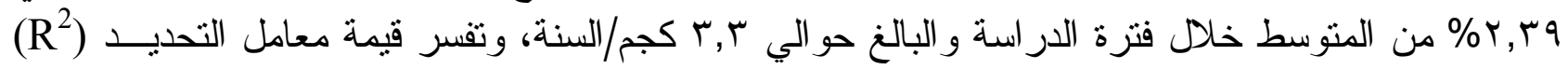

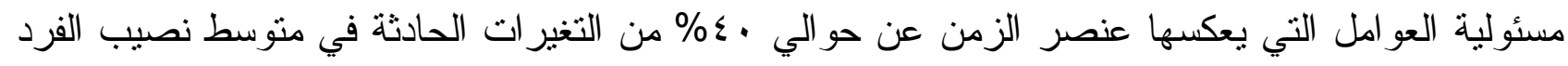

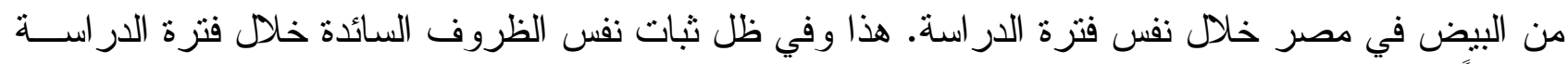

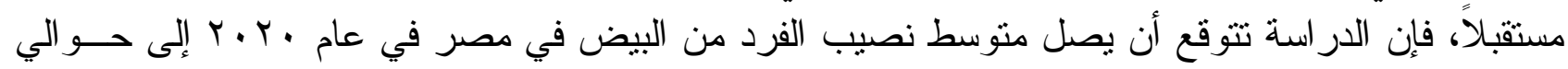
ع

צ- تطور الفجوة الغذائية الظاهرية من البيض في مصر - الاتجاهات العامة والتوقعات المستقبلية :

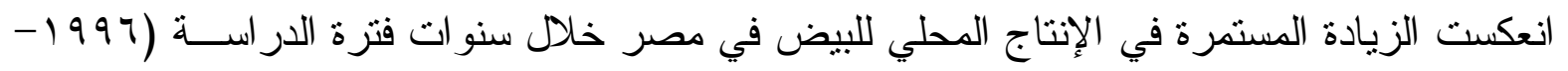

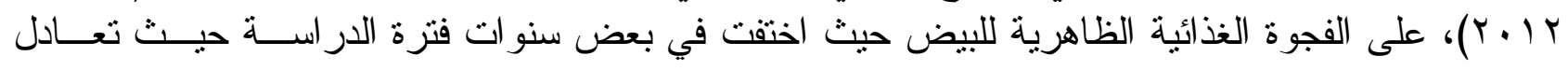
الإنتاج المحلي المصري من البيض مع الاستهلاك المحلي منه في تللك السنوات، بينما ظهرت الفجوة الغذائية من البيض في مصر في سنوات أخرى ضئيلة وتللك تمنل كميات البيض المستوردة و التي تستخدم في إنتـاج

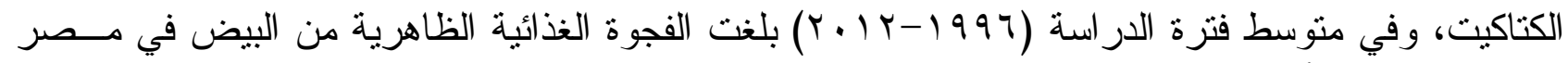

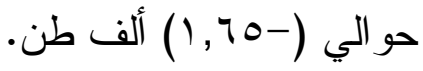

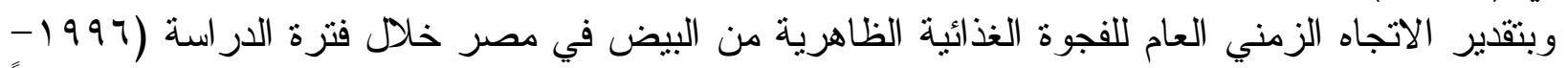

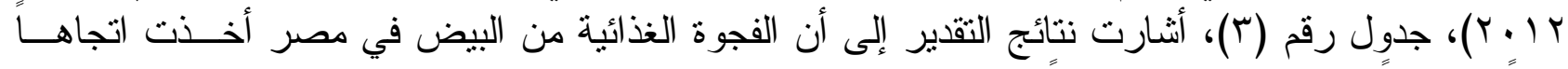

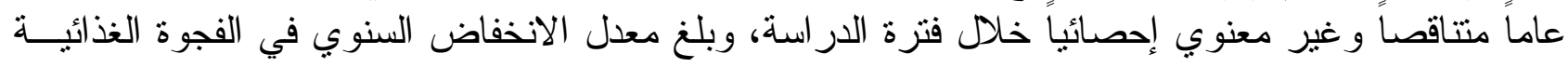

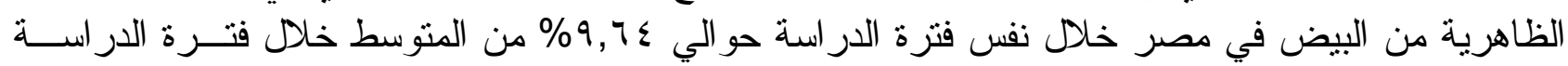

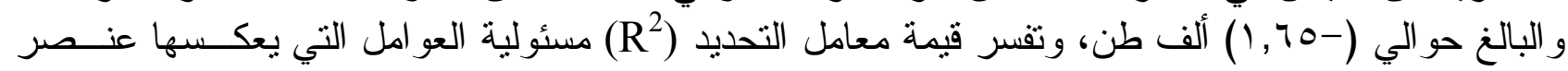

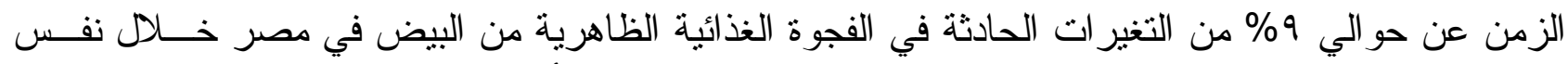

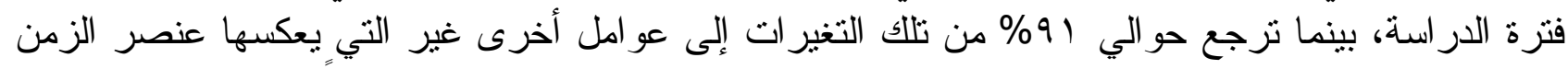

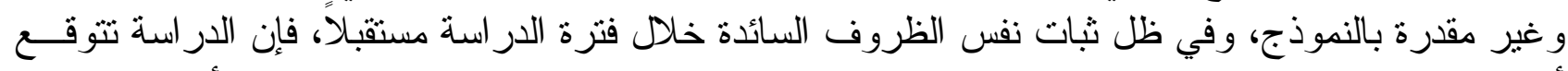

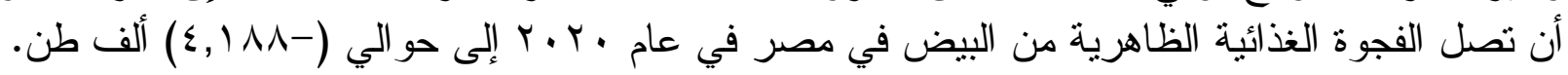

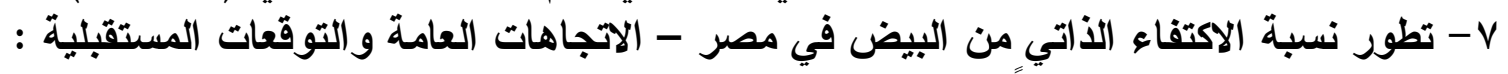

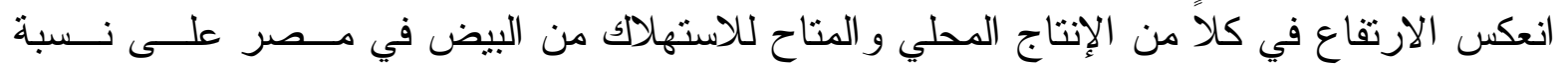

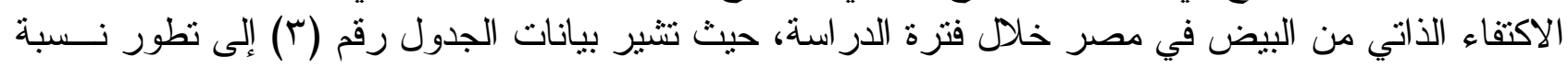

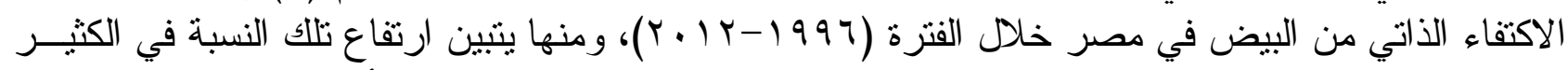

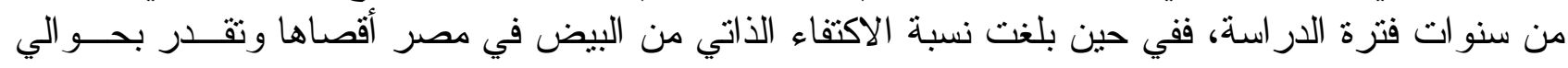

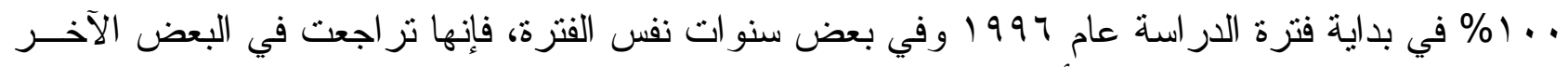

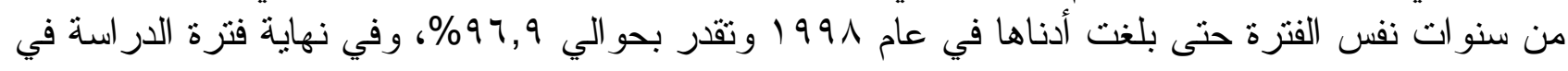

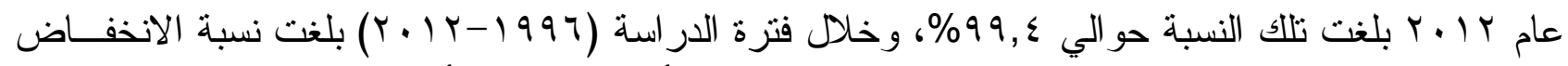

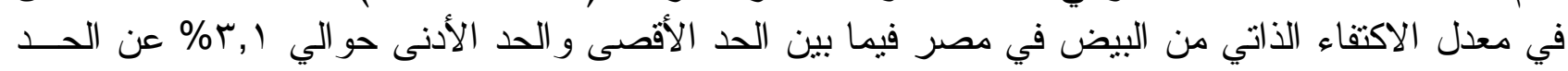

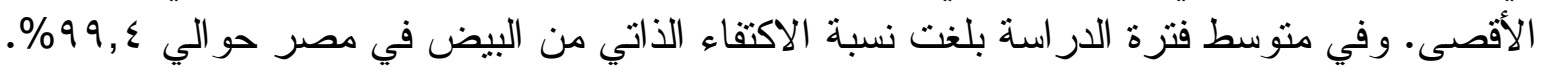

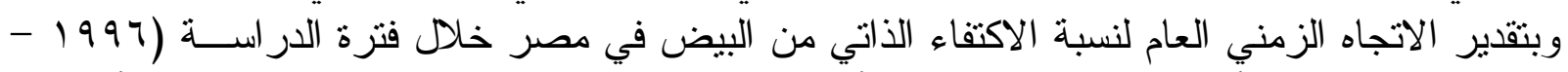

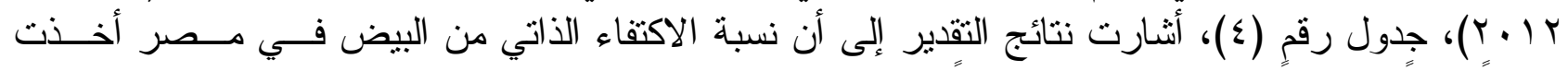

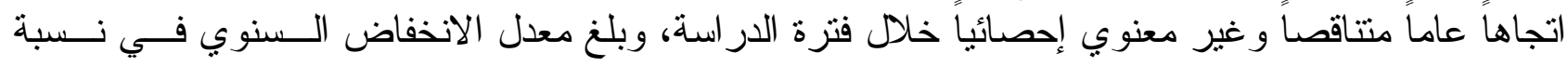

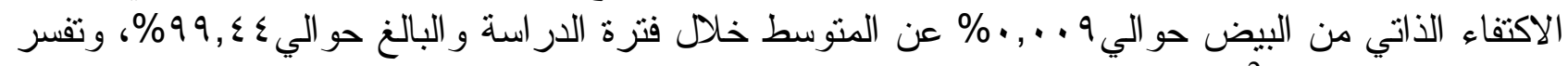

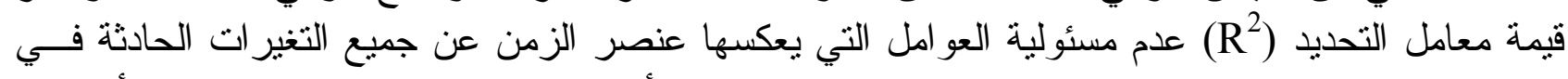

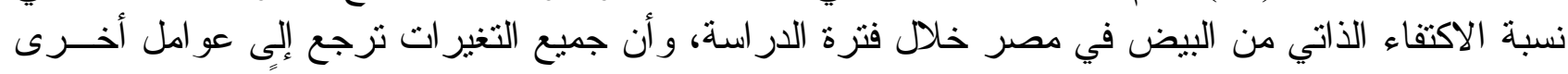

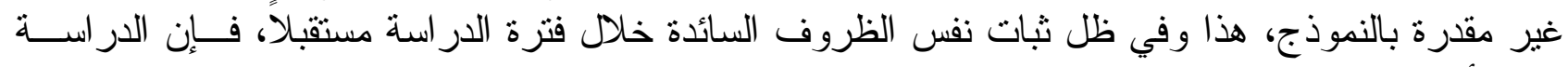

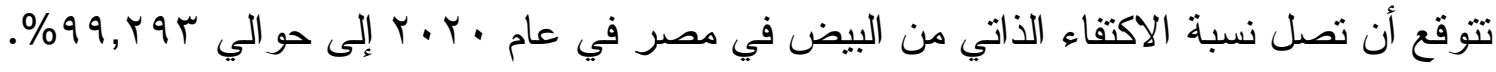



در اسة اقتصادية لإنتاج واستهلاك بض المائدة في جمهورية مصر العربية

جدول رقم (r): تطور الإنتاج المحلي والمتاح للاستهلاك والواردات والصادرات ومتوسط نصيب الفرد

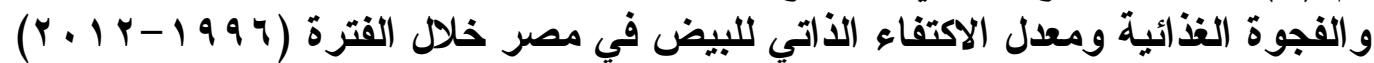

\begin{tabular}{|c|c|c|c|c|c|c|c|c|c|}
\hline نسبة & الفجوة الغذأئية & متوسط & عدد & الغذاو & المتاح & خارجية & التجارة & الإنتاج & البيان \\
\hline الأاتئفاء\% & الظاهرية ألفت & كجيب السنة: & ألف نسمانة & ألف طافي & للأفته طنلّك & ألضف طنّرات & ألفو طن & ألف المَّلَّي & \\
\hline $1 \cdots$ & - & $r, \wedge$ & OQTTK & $17 \mathrm{~V}$ & 19. & - & - & 19. & 1997 \\
\hline $1 \cdots$ & - & $r, \Lambda$ & $7.0 \mathrm{VA}$ & TVI & Y.. & - & - & Y.. & $199 \mathrm{~V}$ \\
\hline 97,9 & $7-$ & $r, V$ & $7 \pi \leq 0$ & $17 \mathrm{~V}$ & 199 & - & 7 & 194 & 1991 \\
\hline 91,9 & $T-$ & $T, T$ & $7 Y 70 Y$ & $T \leqslant \wedge$ & 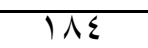 & $\overline{-}$ & $T$ & TAY & 1999 \\
\hline $1 \cdots$ & - & $r, 1$ & $7 r 9 V 7$ & T.. & Trq & $\overline{-}$ & - & Trq & $r \ldots$ \\
\hline $1 \cdots$ & $\overline{-}$ & $r, \varepsilon$ & 70 7017 & TYY & TVI & - & - & TVI & $r \ldots l$ \\
\hline $1 \cdots$ & - & $\varepsilon, \cdot$ & $7 \vee 9 \vee 7$ & r7q & Trt & - & - & Trt & $r \ldots r$ \\
\hline $1 \cdots$ & - & $r, \Lambda$ & $7 V 9.1$ & TOV & TYY & - & - & TYY & $r \ldots r$ \\
\hline $1 \cdots$ & - & $r, q$ & $79 \pi \%$. & r7q & TMO & - & - & Tro & Y.. \\
\hline $99, \pi$ & $r-$ & $r, 1$ & $V .771$ & TIV & TVY & - & $T$ & TV. & $r \ldots 0$ \\
\hline $1 \cdots$ & - & $T \cdot \varepsilon$ & $V r \ldots q$ & $T V T$ & $T \varepsilon \varepsilon$ & - & - & Tा纟 & $r . .7$ \\
\hline 99,7 & $1-$ & $r, q$ & $V M 700$ & भा & $r \wedge$. & - & $T$ & TVq & $r \cdot V$ \\
\hline $1 \cdots$ & - & $r, 0$ & VOYYO & TYE & T07 & - & - & To7 & $r \cdot \Lambda$ \\
\hline 99,1 & $\Gamma-$ & $r, 0$ & VIAYT & TAV & דו & - & $r$ & TrT & $r . .9$ \\
\hline $9 \vee, 0$ & $1 \cdot-$ & $\varepsilon, 1$ & VAVKA & TrY & $\varepsilon \cdot \wedge$ & - & 1. & rq1 & $r \cdot 1$. \\
\hline 99,1 & $1-$ & $\varepsilon, 1$ & $\Lambda \cdot \xi) \cdot$ & TTY & हा & $\Gamma$ & $\varepsilon$ & हा. & $r \cdot 11$ \\
\hline $99, \varepsilon$ & $r-$ & $\xi, \xi$ & AYOO. & rq7 & $\varepsilon \vee 0$ & 1 & $\varepsilon$ & $\varepsilon V Y$ & $r \cdot I r$ \\
\hline $99, \xi$ & $1,70-$ & $\Gamma, \Gamma$ & $7998 \cdot, 7$ & Trq,A & Y91,1 & $\cdot, Y \Sigma$ & $1, \vee \wedge$ & Y90,r & المتوسط \\
\hline
\end{tabular}

المصدر : جمعت وحسبت من : المبنة

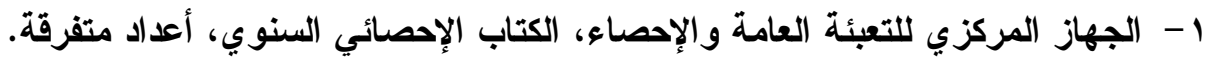

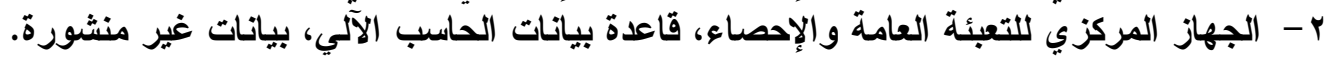

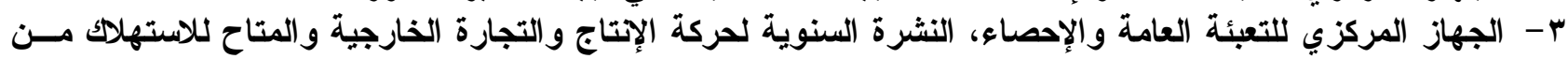

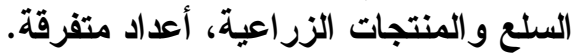

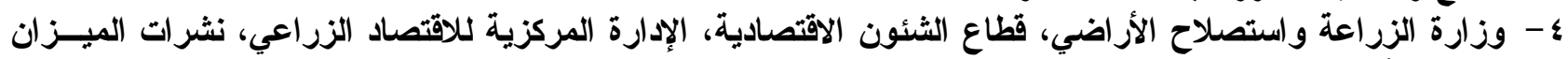
الغذائي، أعداد متفرقة.

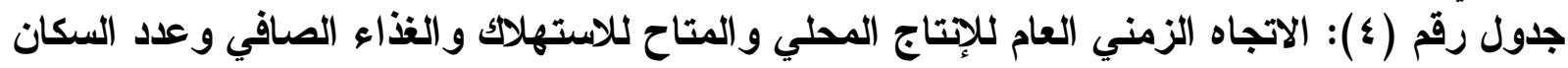

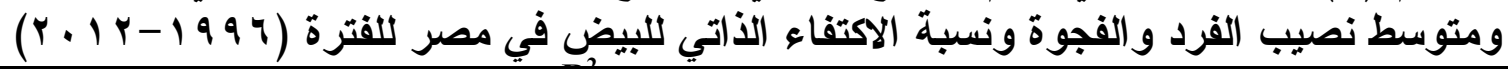

\begin{tabular}{|c|c|c|c|c|c|c|c|c|}
\hline المتوقع عام & \% معدل & مقدار التغيز & متوسط & معامل & F المقدرة F & دالة الاتجاه الزمني العام & المتغير ات & م \\
\hline Or.,人ษr & $\varepsilon, 99$ & $1 \varepsilon, V Y r$ & rq०,rq & $\cdot, \vee \vee r$ & $* * \varepsilon \wedge, 1 \wedge \varepsilon$ & 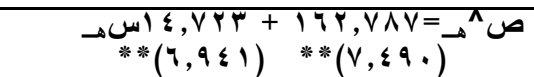 & & $T$ \\
\hline orq,1 & 0,11 & $1 \varepsilon, \wedge \wedge r$ & rq1, . & $\cdot, \vee \bullet 0$ & $* * \varepsilon \neg, r q r$ & 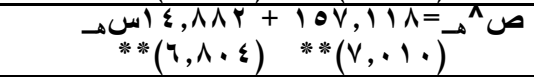 & آن & $Y$ \\
\hline$\varepsilon \cdot r, \wedge 0$. & $\leq, \leq 1$ & $1 \cdot, \leqslant 4 q$ & $r r q, \wedge r$ & $\cdot, 771$ & $* * r \cdot, r \leqslant V$ & 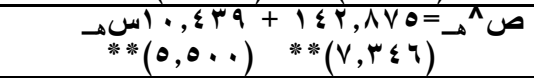 & (ألغاء ألم ط & $\Gamma$ \\
\hline QYAY\&,A & $r, \cdot \varepsilon$ & $1 \leq r \wedge, r \cdot 1$ & $799 \vee \cdot, 7$ & $\cdot, 99 \leq$ & $* * r \cdot, q \mu$ & 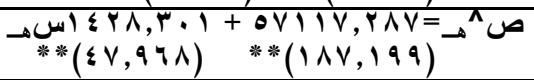 & (ألف نسم السكانئ) & $\varepsilon$ \\
\hline$\varepsilon, 7 Y \varepsilon$ & r, rq & $\cdot, \wedge$ & $r, r \leq 1$ & $\cdot$ • & $* \because, \vee \vee \neg$ & 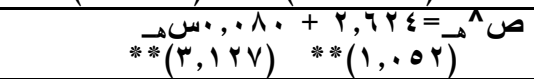 & متوسط نصيخبة & 0 \\
\hline$\varepsilon, \mid \wedge \wedge-$ & $9,7 \leq-$ &., $109-$ & $1,70-$ & $\cdot, \cdot \wedge \wedge$ & $1, \leqslant \leqslant 0$ & 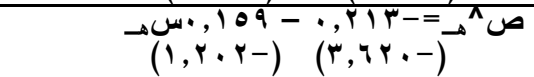 & 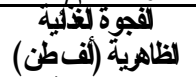 & 7 \\
\hline$q q, r q 4$ & $\cdot, \cdot \cdot 9-$ & $\cdot, \cdot 9-$ & $99, \leq \leq$ & $\cdot, \cdots r$ & מ & 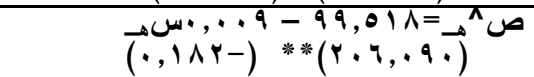 & الاكتفاء الأبة ن & $\mathrm{V}$ \\
\hline
\end{tabular}

* يشير الرقم بين القوسين أسفل الثوابت ومعاملات الاحدار في جميع المعادلات إلى قيمة (t) المحسوبة.

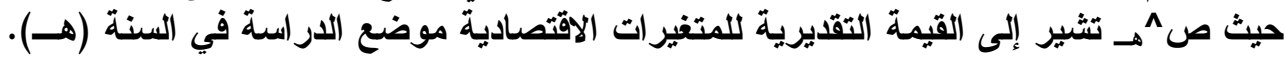

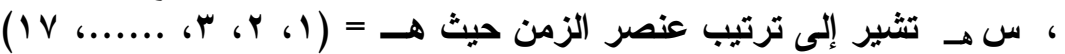
معامل التحديد

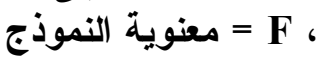
(*) معنوي عند مستوى (0., (•)

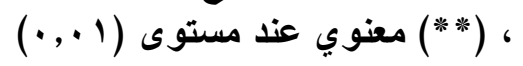

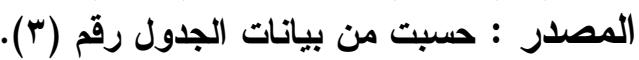




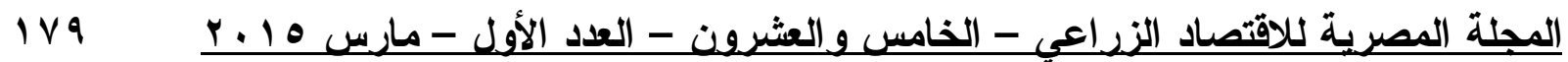

ثالثاًَ- تطور متوسط نصيب الفرد من بيض المائدة في مصر - الاتجاهات العامة والتوقعات المستقبلية:

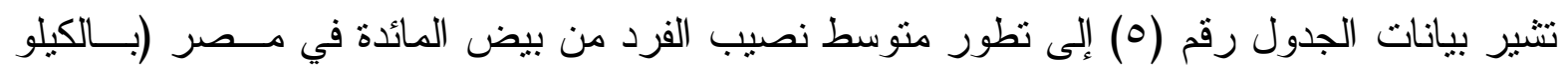

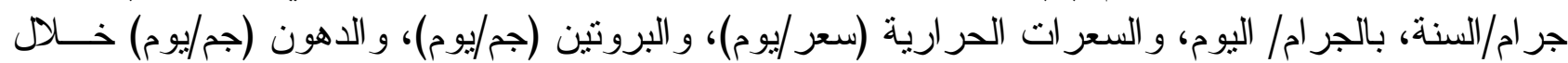

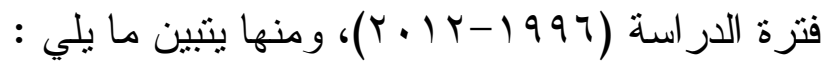

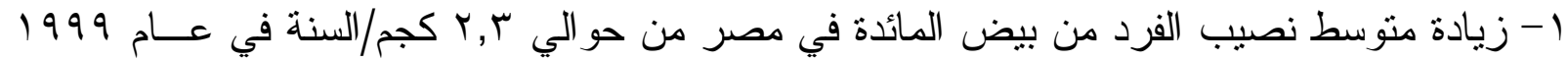

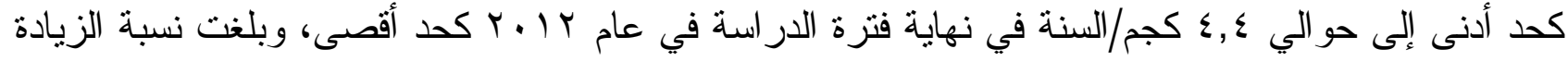

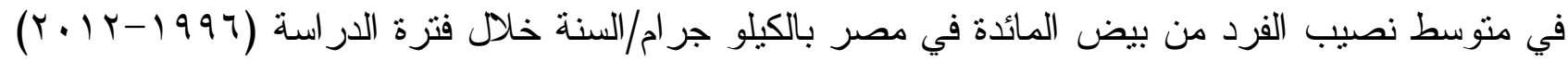

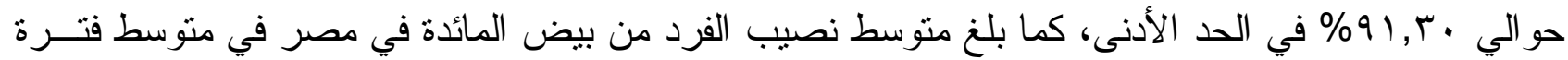

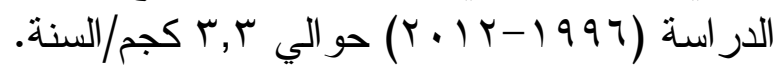

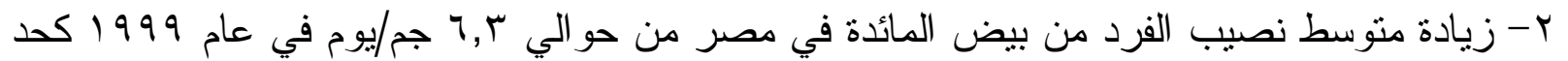

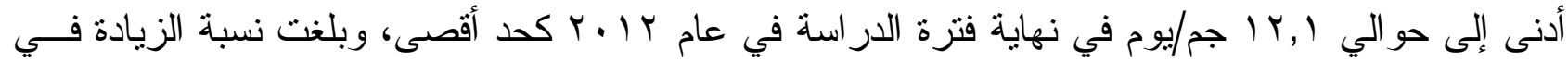

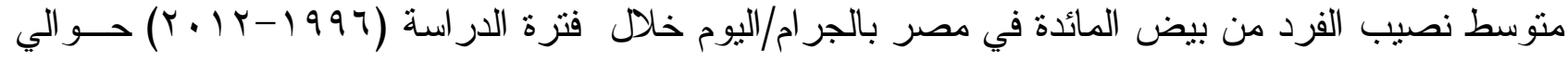

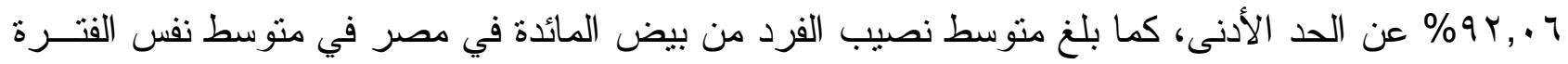
حو الي 1 ( 9 جم/يوم.

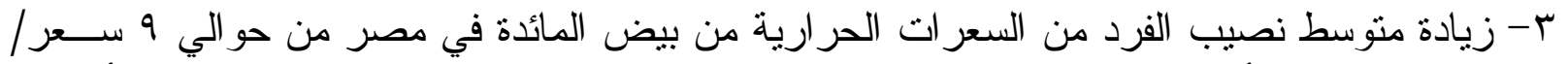

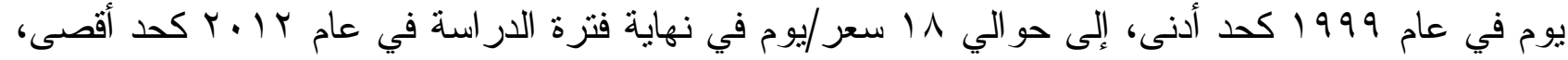

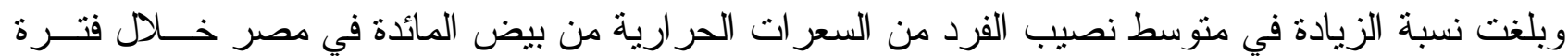

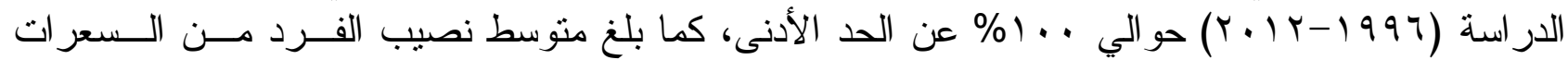

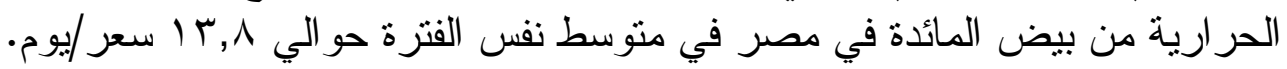

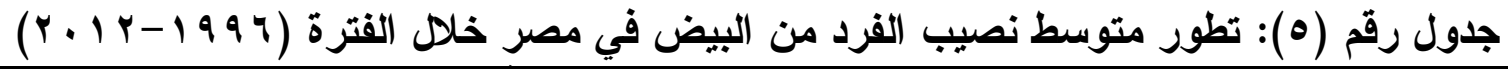

\begin{tabular}{|c|c|c|c|c|c|}
\hline الدهون جم/يوم & البروتين جم/يوم & سعر /السعرات الحرارية & جم/يوم & كجم/السنة & السنوات البيان \\
\hline$\cdot, 9$ & $1, \cdot$ & IT & $V, 7$ & $T, \Lambda$ & 1997 \\
\hline$\cdot, 9$ & $1, \cdot$ & IT & $\mathrm{V}, \mathrm{V}$ & $r, \Lambda$ & $199 \mathrm{~V}$ \\
\hline$\cdot, 9$ & $1, \cdot$ & Ir & $\vee, \varepsilon$ & $r, V$ & 1991 \\
\hline$\cdot, \mathrm{V}$ & $\cdot, \wedge$ & 9 & $7, r$ & r r r r & 1999 \\
\hline$\cdot, 9$ & 1,1 & $\pi$ & $\Lambda, 0$ & $r, 1$ & r... \\
\hline 1, & $1, r$ & $1 \varepsilon$ & $9, r$ & $\uparrow, \varepsilon$ & $r \ldots 1$ \\
\hline $1, r$ & $1, \varepsilon$ & 17 & $11,$. & $\varepsilon, \cdot$ & $r \ldots r$ \\
\hline 1,1 & $1, r$ & 10 & $1 \cdot, \varepsilon$ & $\Gamma, \Lambda$ & $r \ldots r$ \\
\hline $1, r$ & 1, & 17 & $1 \cdot, V$ & $r, q$ & r... \\
\hline$\cdot, 9$ & 1,1 & Tr & $\Lambda, 0$ & $r, 1$ & r... \\
\hline$\cdot, \mathrm{V}$ & $\cdot, \wedge$ & 1. & 7,7 & $r, \varepsilon$ & $r \ldots q$ \\
\hline$\cdot, 9$ & 1, & ir & $\vee, 9$ & $r, q$ & $r . . v$ \\
\hline $1, \cdot$ & $1, r$ & $1 \leqslant$ & 9,7 & $r, 0$ & $r . \Lambda$ \\
\hline $1, \cdot$ & $1, r$ & $1 \leqslant$ & 9,7 & $r, 0$ & $r \ldots q$ \\
\hline $1, r$ & $1, \varepsilon$ & iv & $11, r$ & $\varepsilon, 1$ & $r \cdot 1$. \\
\hline 1,0 & $1, \varepsilon$ & iv & $11, r$ & $\varepsilon, 1$ & $r \cdot 11$ \\
\hline r & 1,0 & 11 & $\mid r, 1$ & $\varepsilon, \varepsilon$ & $r \cdot I r$ \\
\hline $1, \cdot$ & $1, Y$ & $T \Gamma, \Lambda$ & 9,1 & $\Gamma, \Gamma$ & المتوسط العام \\
\hline
\end{tabular}

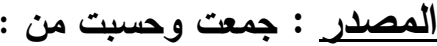

1- وزعل وارة الزراعة واستصلاح الأراضي، قطاع الشئون الاقتصادية، الإدارة المركزية للاقتصاد الزراعي، النشرة الـسنوية

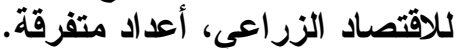

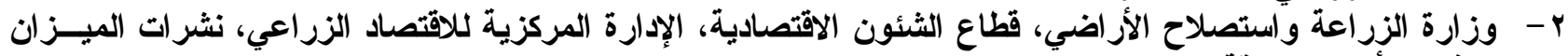
الغذائي، أعداد متفرقة.

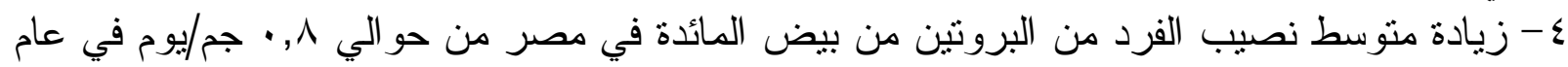
999 1 99 


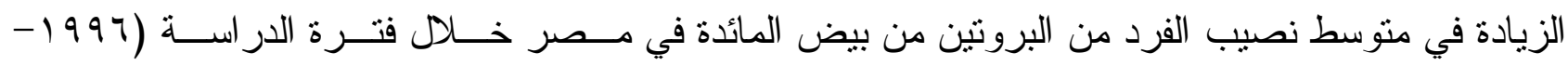

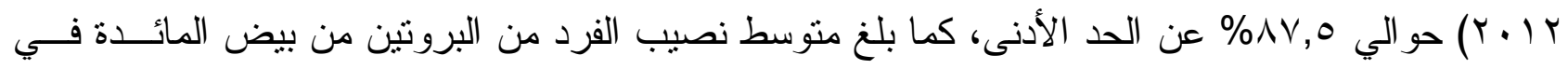

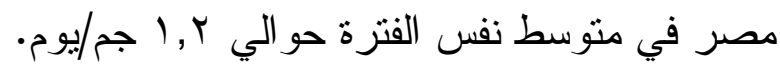

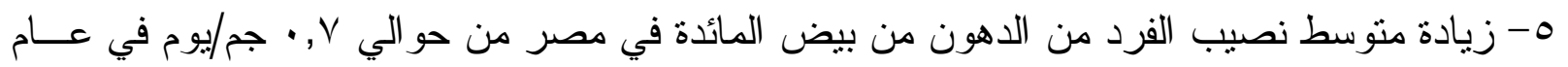

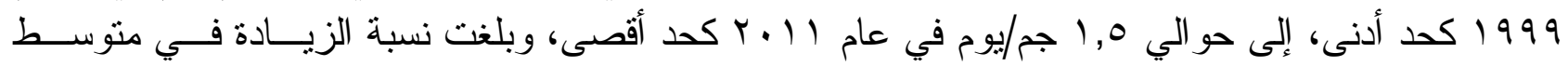

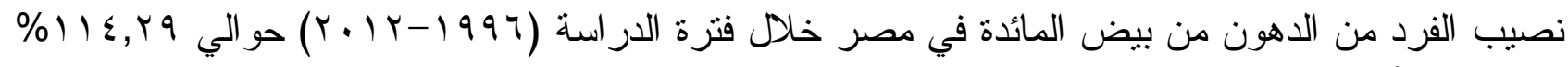
عن الحد الأدنى، كما بلغ منوسط نصيب الفرد من الدهون من بيض المائدة في مصر في منوسط نفس الفنزة

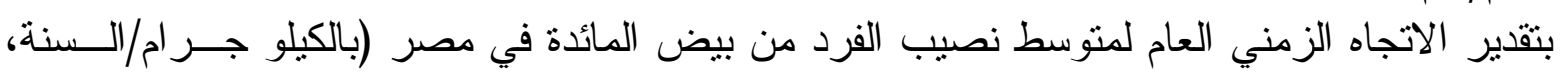

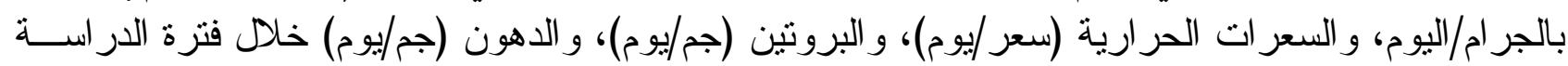

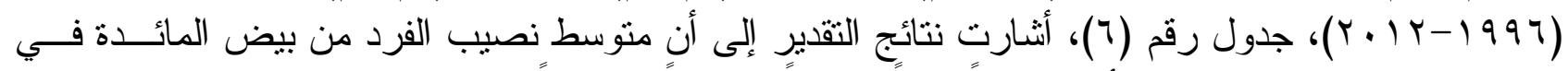

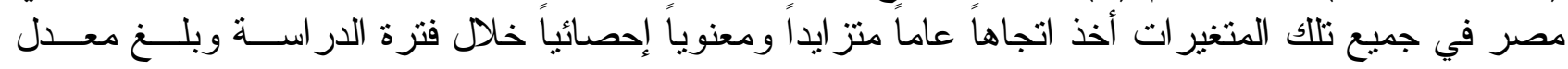

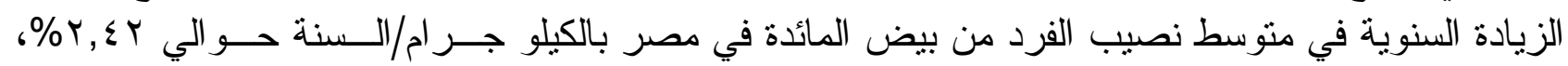

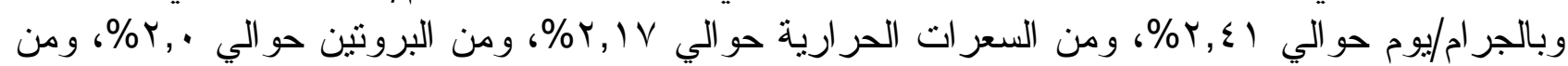

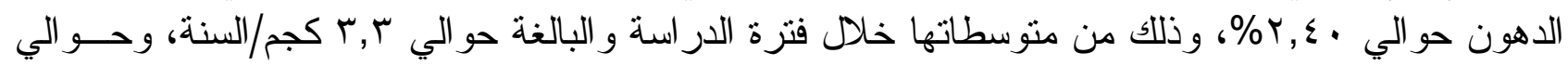

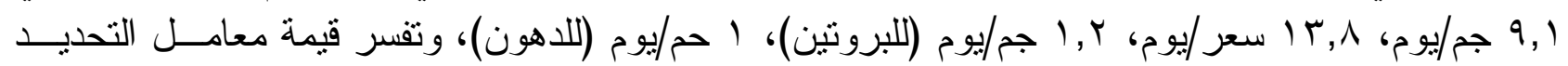

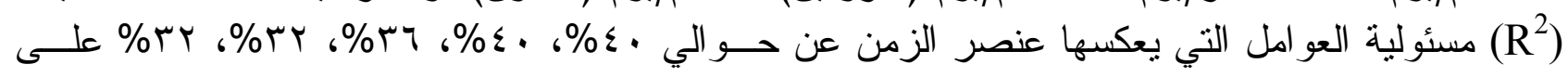

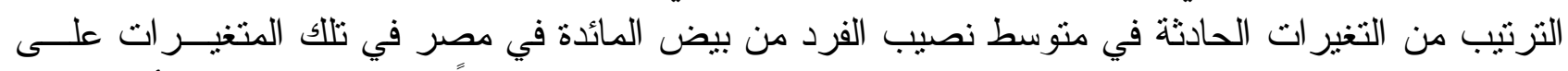

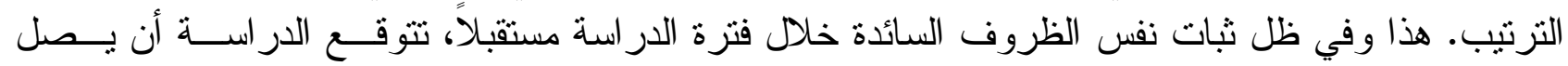

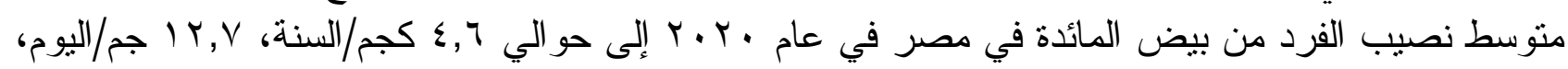

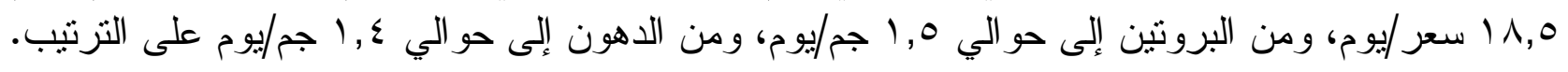

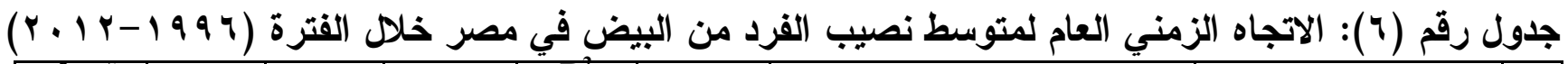

\begin{tabular}{|c|c|c|c|c|c|c|c|c|}
\hline المامقع & 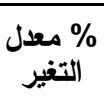 & التغير & الظتوسط & $\begin{array}{l}\text { التحايد } \\
\mathbf{R}^{2}\end{array}$ & المقدرة & دالة الاتجاه الزمني العام & المتغيرات & p \\
\hline 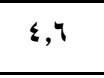 & $r, \leqslant \varphi$ & $\cdot, \wedge$. & $r, r$ & • r ra & $* 9, \vee \vee ५$ & 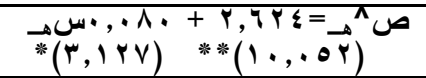 & 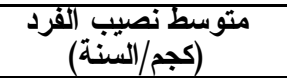 & 1 \\
\hline $1 Y, V$ & $r, \varepsilon 1$ & $\cdot, r 19$ & 9,1 & • & $* 9, \vee \wedge$. & $\begin{array}{l}\text { صA } \\
\text { ص }\end{array}$ & متوسط نصيب ألفرد & r \\
\hline 11,0 & r,IV & •, Ү१९ & $1 \%, \Lambda$ & ודי & $* \wedge, \S \vee \leqslant$ & 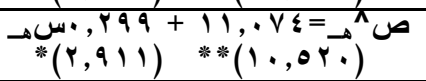 & متوسط (ستصيب) الفرد & $r$ \\
\hline 1,0 & $r, \cdots$ & •, $+Y \varepsilon$ & $1, r$ & • & $* \vee, 1 Y q$ & 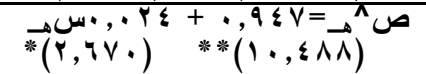 & 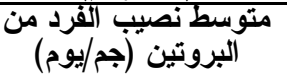 & $\varepsilon$ \\
\hline $1, \varepsilon$ & $\curlyvee, 乏$. & ,,$r \leqslant$ & $1, \cdot$ & • & $* \vee, \cdot V^{4}$ & 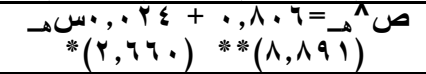 & متوسط نصيب الفرمد من & - \\
\hline
\end{tabular}

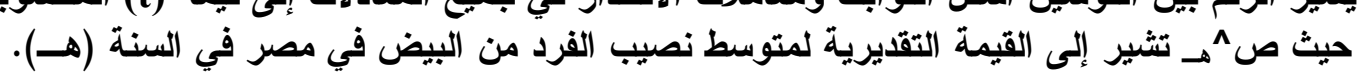

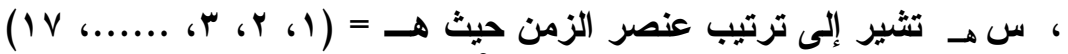

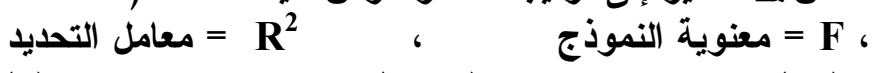

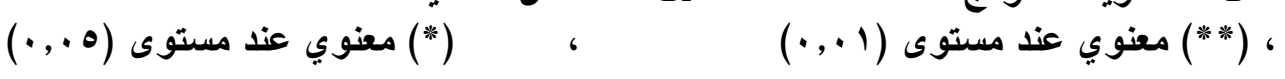

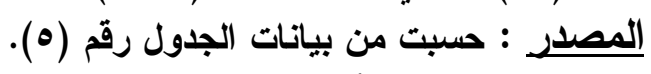

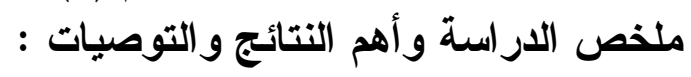

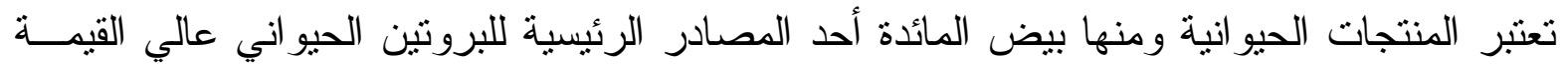

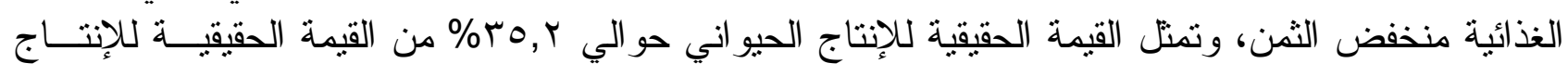

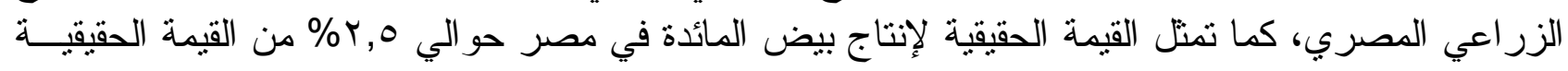




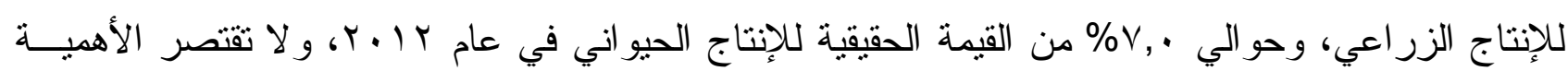

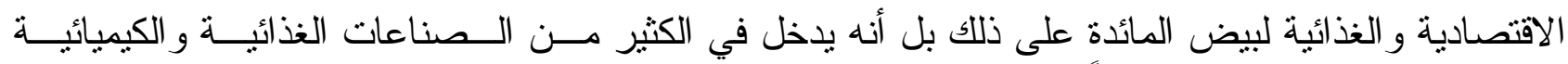

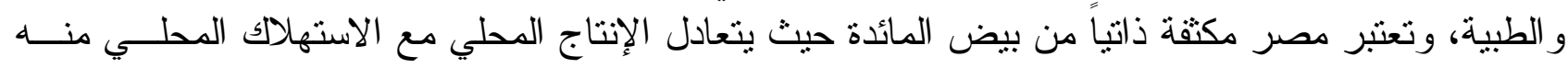
فيما عدا كميات صغيرة مستوردة منه لإنتاج الكتاكيت.

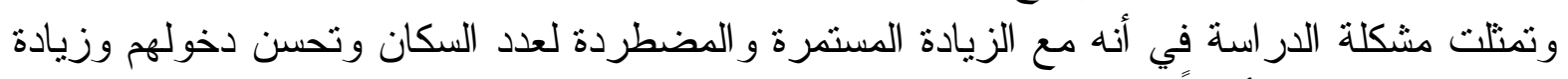

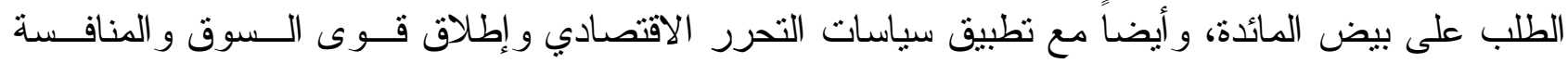

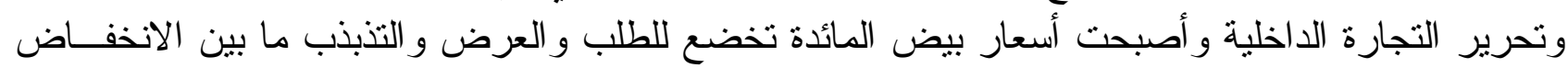

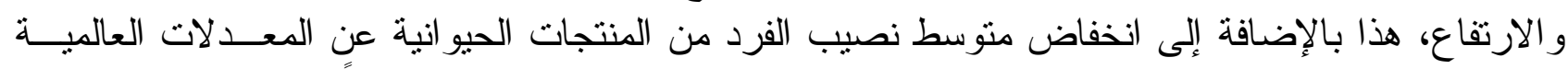

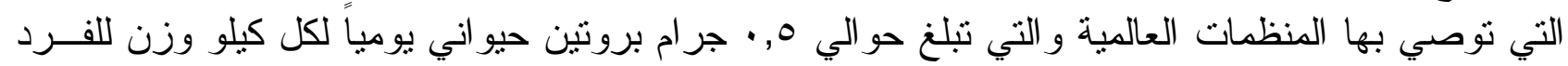

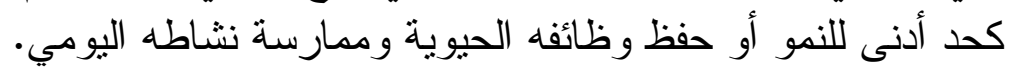

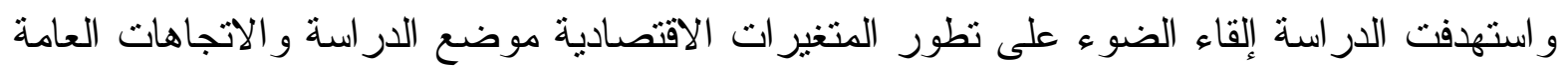

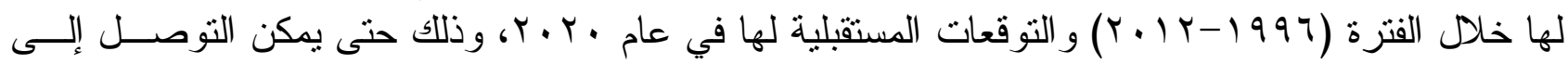

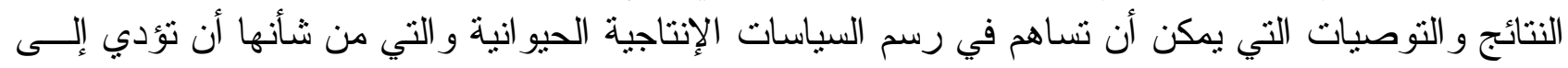

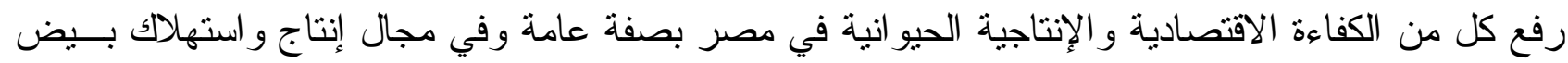

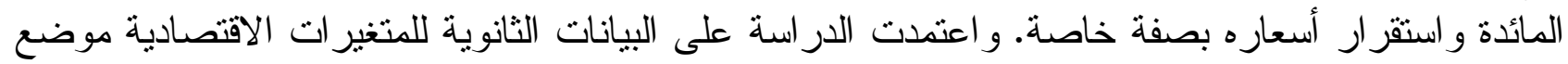

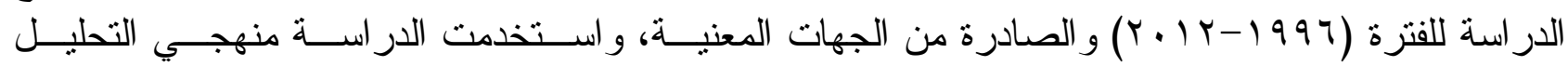

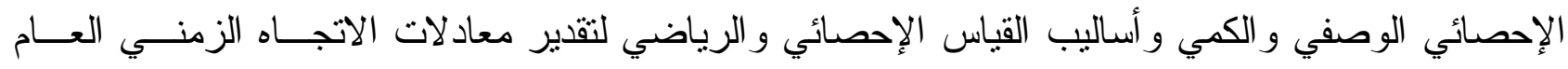
للمتغير ات و التوقعات المستقبلية لها.

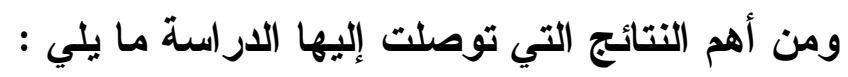

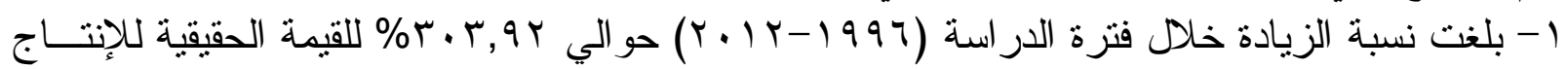

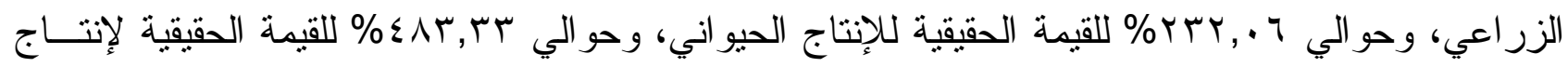

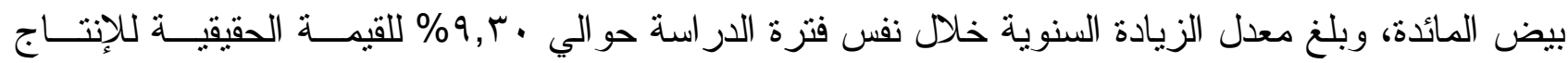

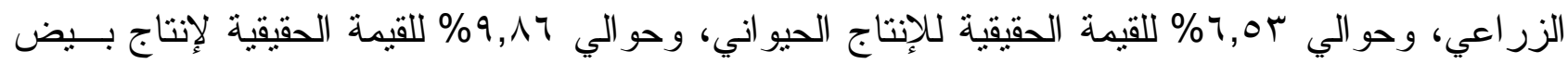

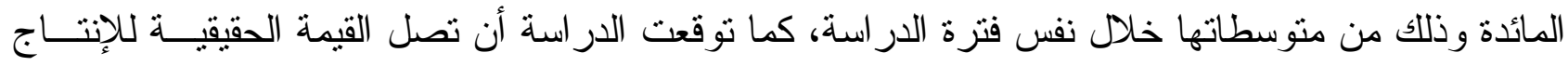

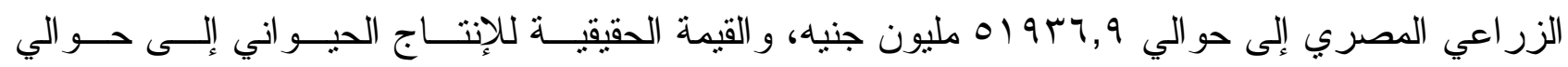

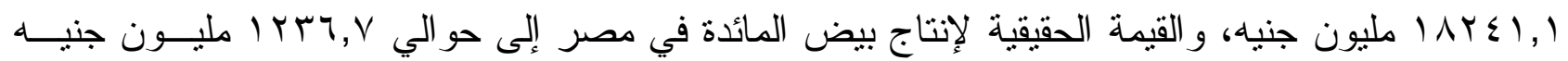

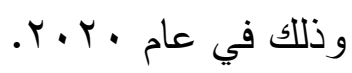

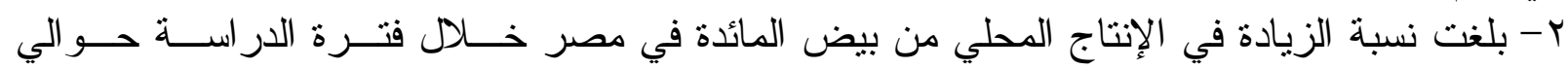

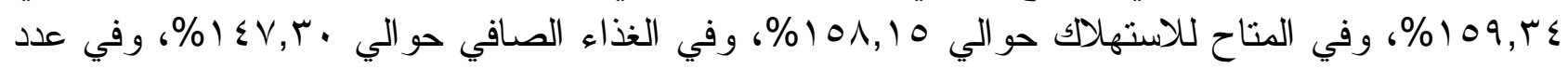

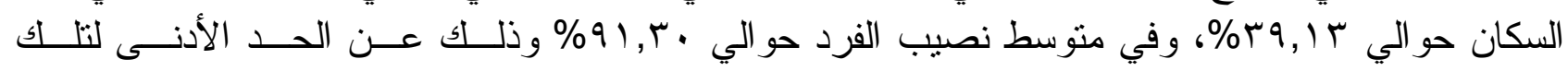

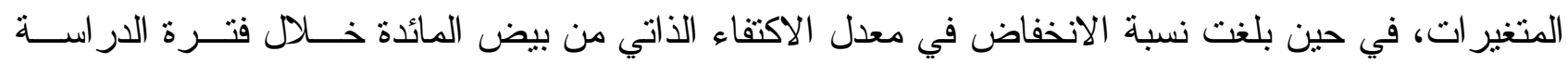
حو الي ا,r\% عن الحد الأقصى.

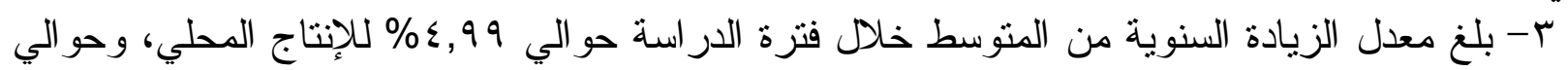

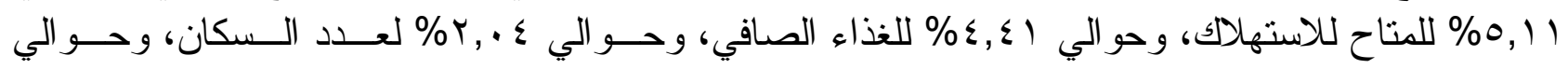

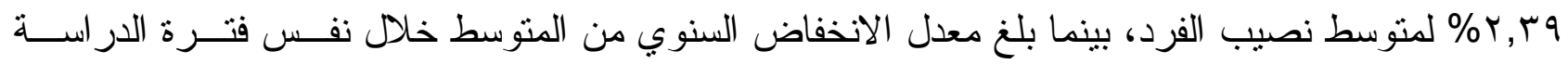

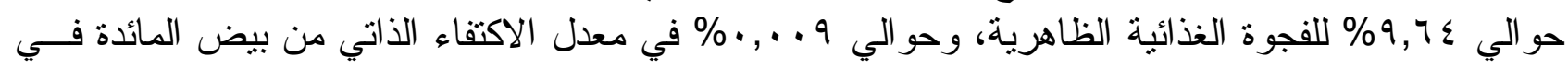
مصر وذللك من متوسطاتها خلال نفس فترة الدر اسة.

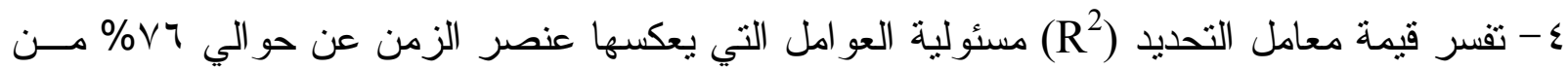

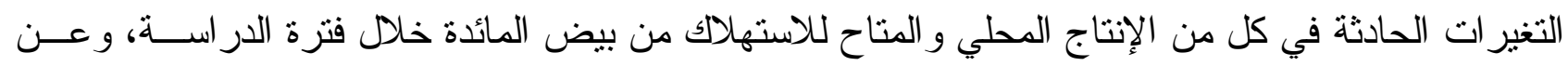




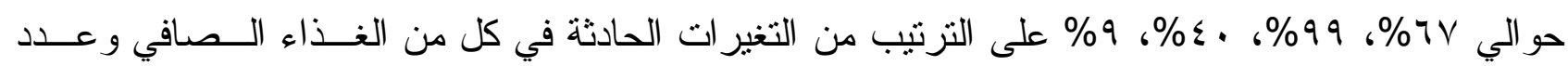

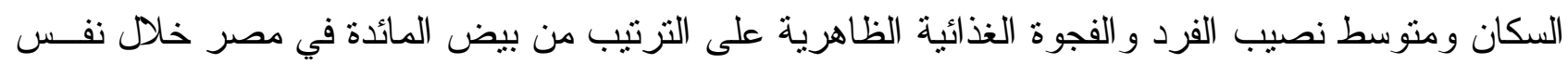

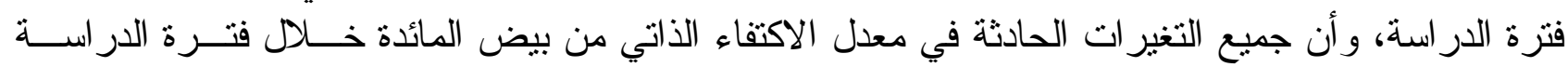

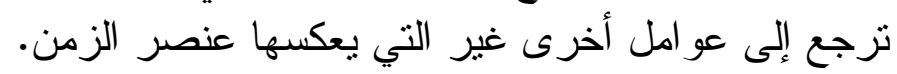

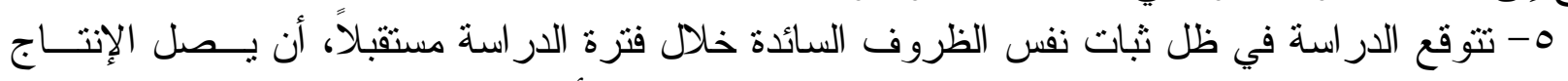

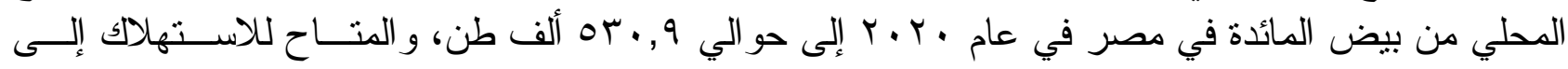

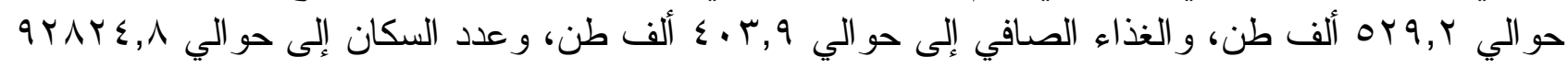

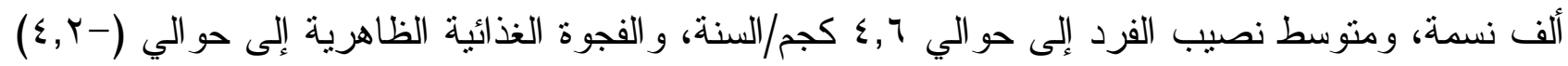

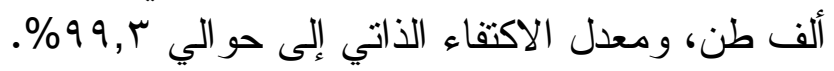

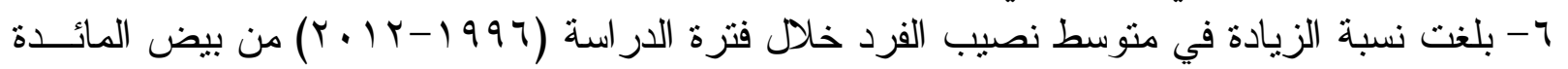

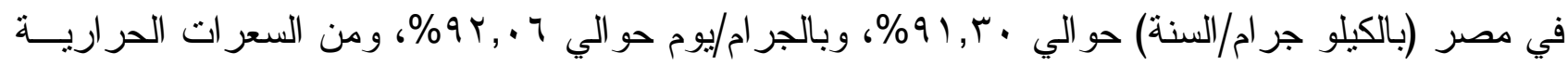

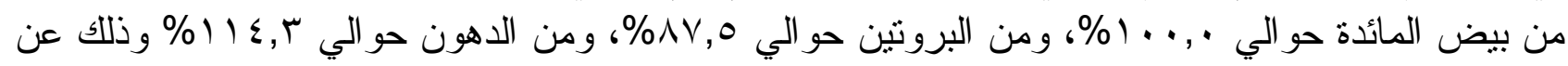

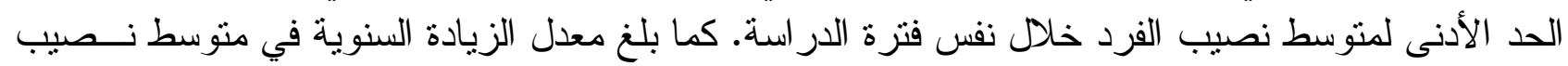

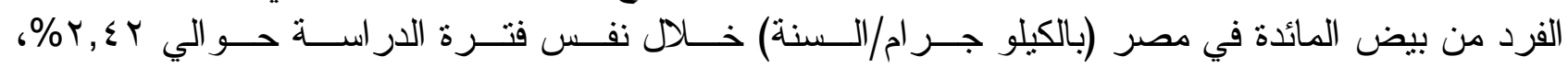

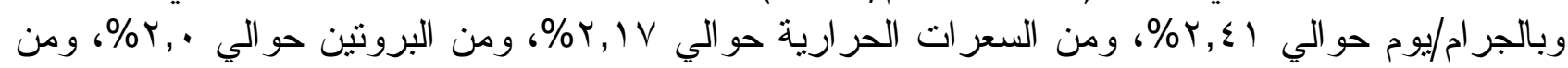

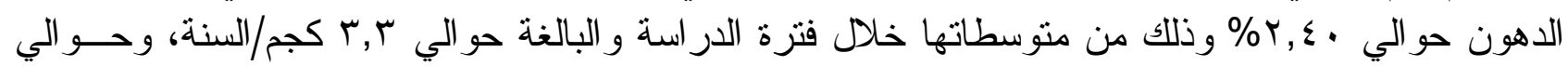

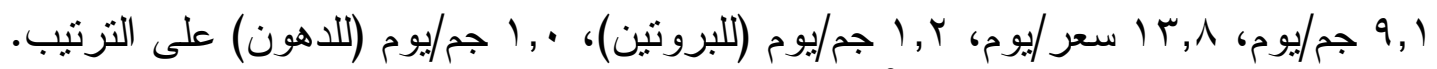

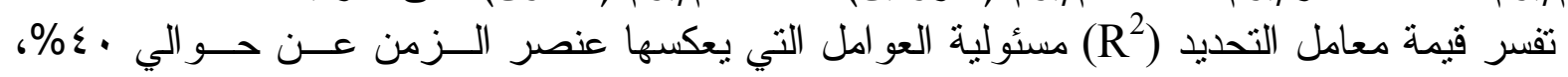
• .

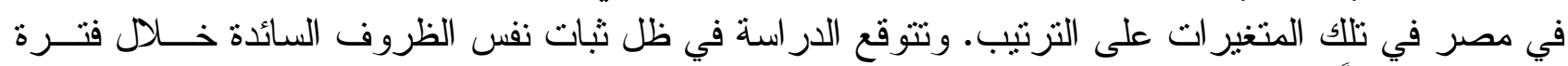

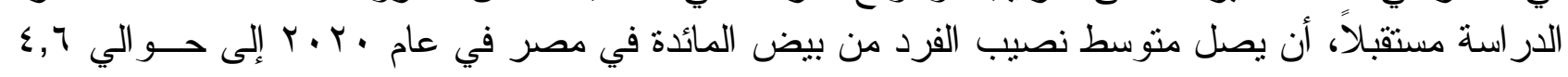

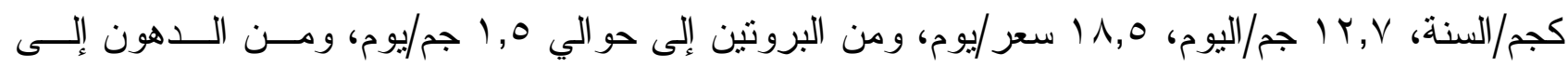

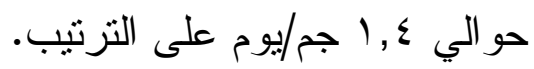

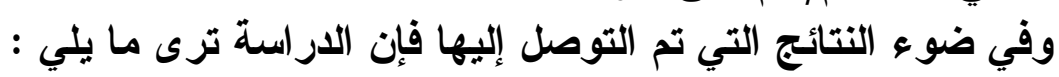

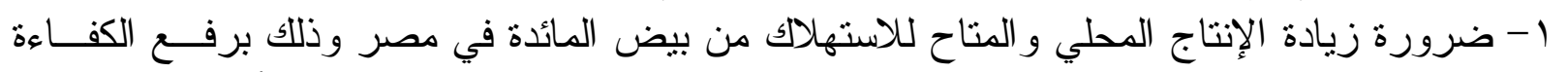

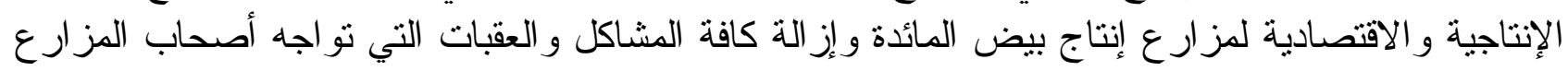

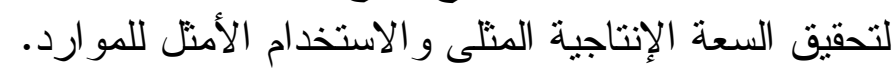

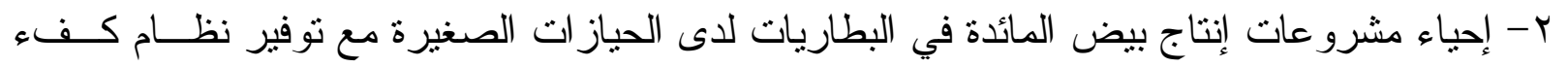

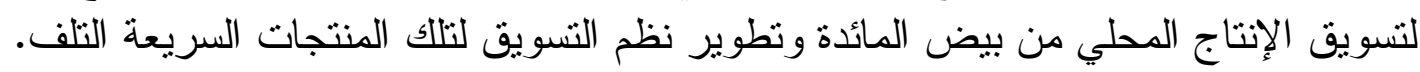

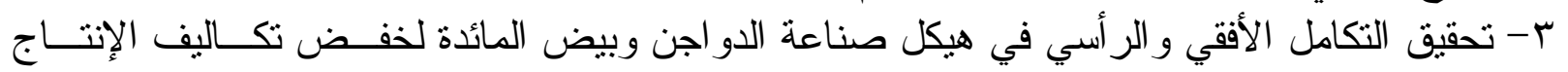

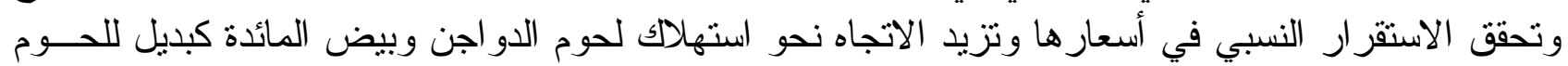
الحمر اء منخفض الثمن.

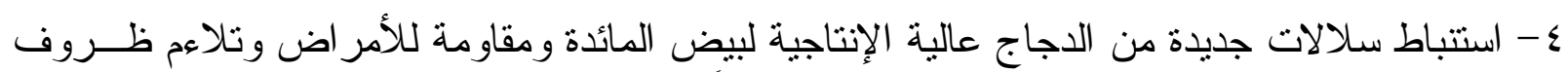

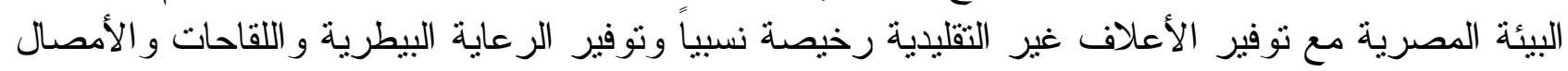
لعلاج الأمر اض بمجرد ظهور ها.

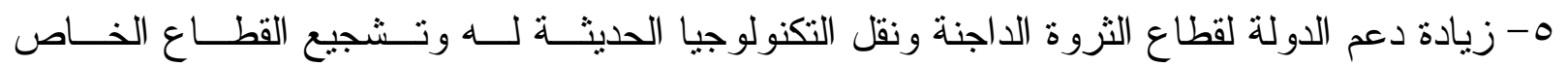

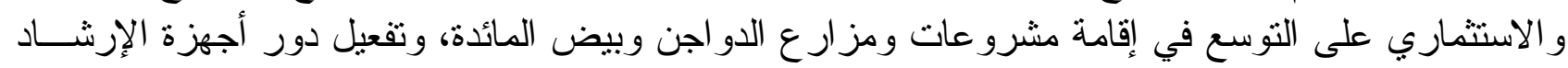

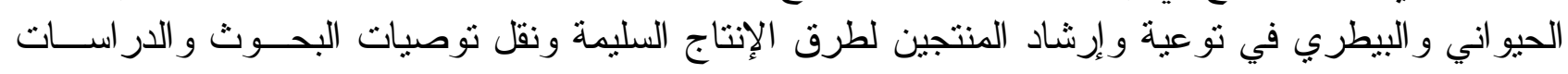




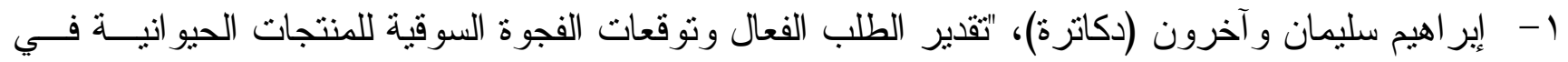

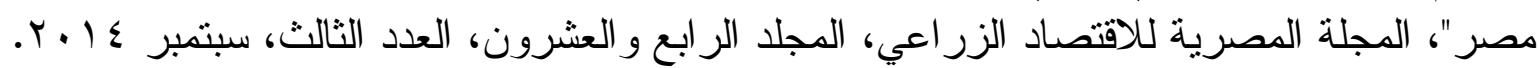

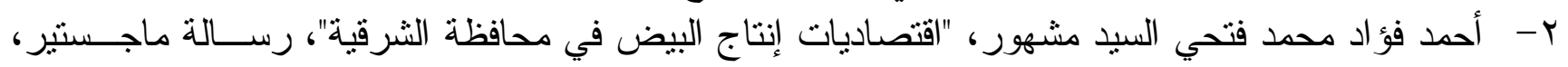

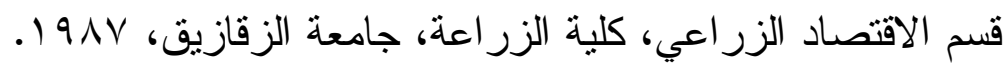

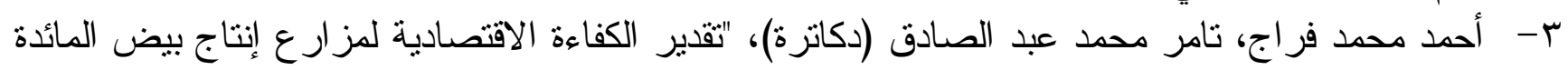

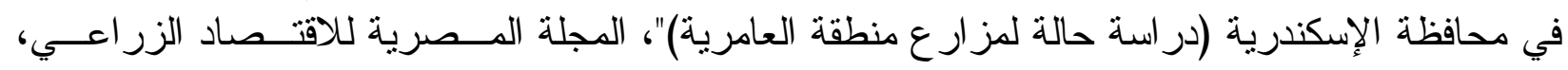

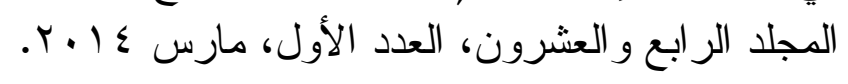

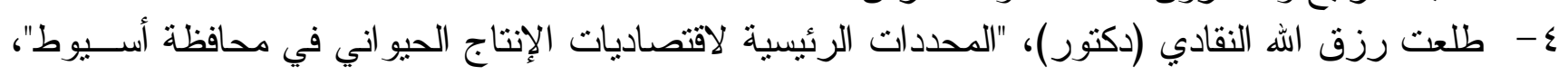

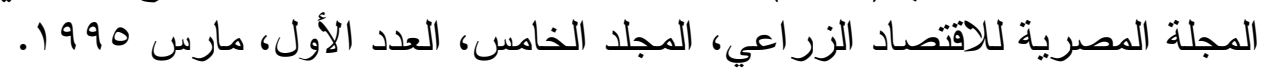

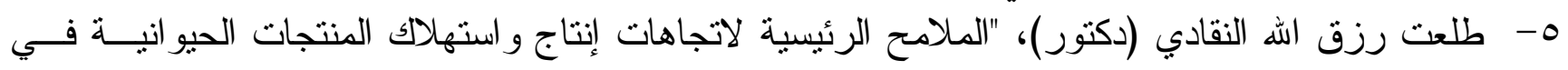

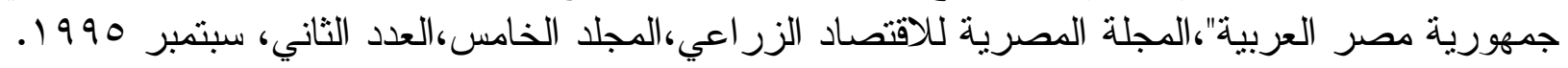

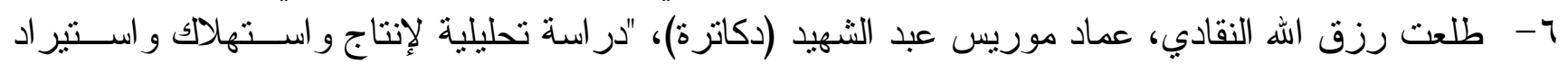

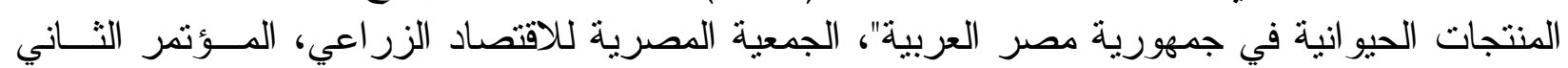

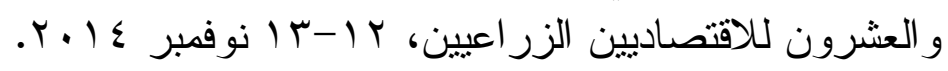

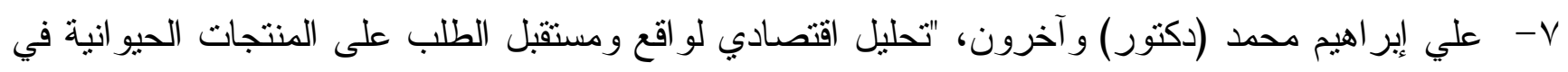

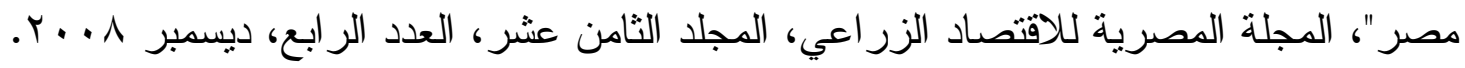

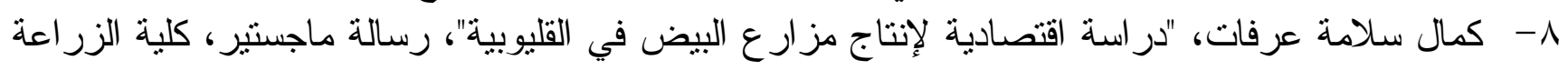

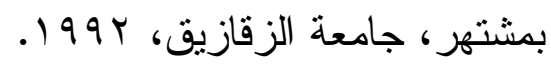

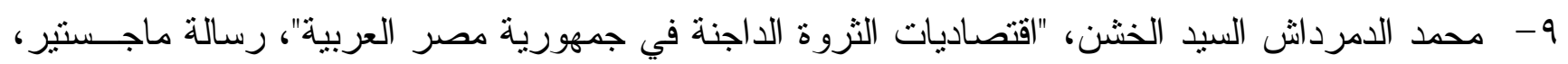

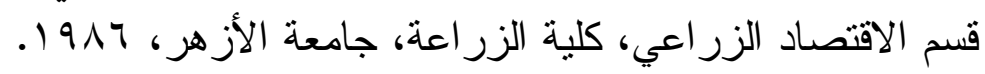

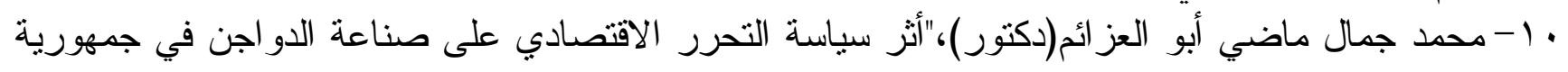

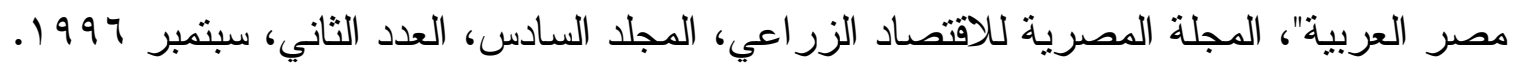

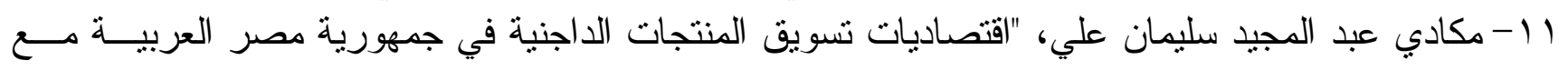

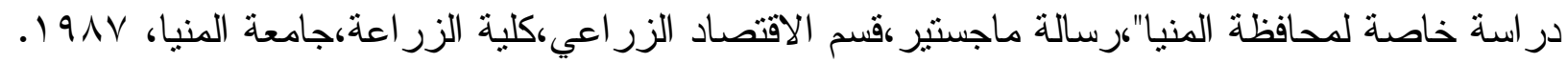

12- Leftwich R.H. The price system and resource allocation, rimeham and Company New York PP, 20-21, 1975.

النشر ات العربية : النشية - - الجهاز المركزي للتعبئة العامة و الإحصاء - الكتاب الإحصائي السنوي - القاهرة - أعداد متفرقة.

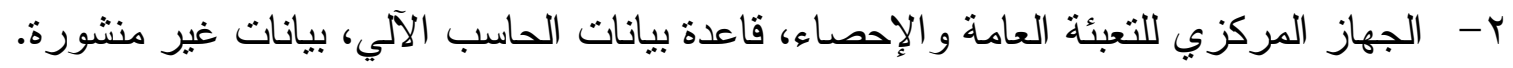

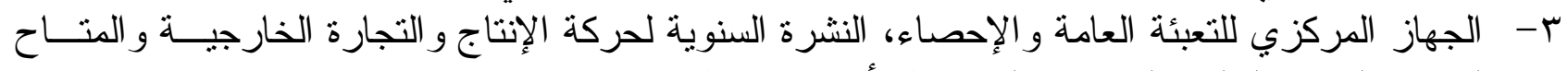

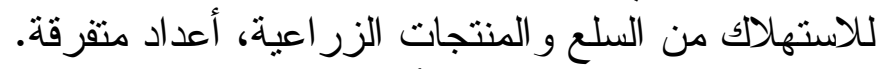

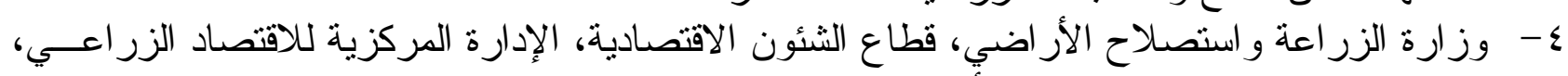

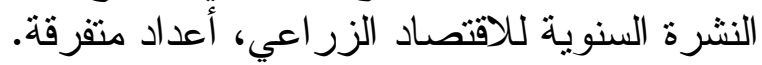

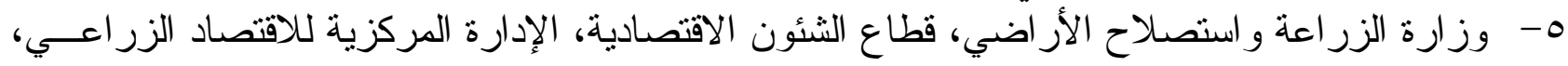

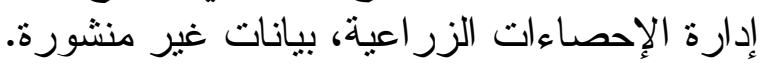

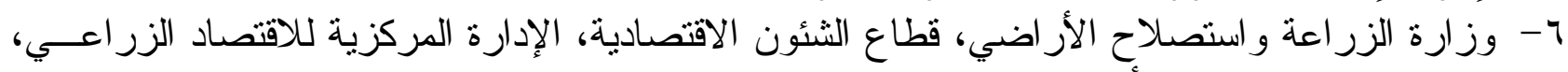

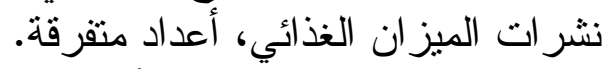

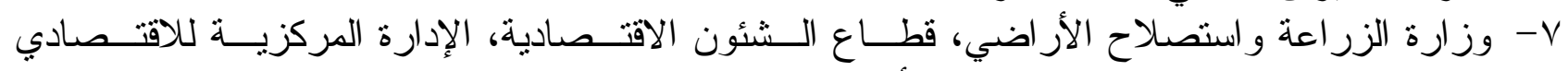

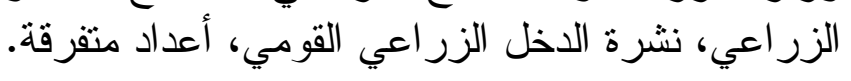




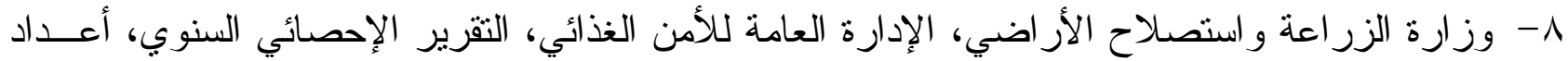

9- الموقع الالكتروني لمنظمة الأغذية و الزر اعة للأمم المتحدة (F.A.OW.fao.org (

\section{An Economic Study For Production And Consumption Table Eggs In Of Egypt}

\section{Prof. Dr. Talaat Razkalla El-Nakady Dr. Emad Moris Abdel Shaheed \\ Dr. Youssef Tawfik Girgis}

\section{Agricultural Economics Research Institute, Agricultural Research Center}

\section{Summary and Recommendations}

The study aimed to shed light on production and consumption table eggs in Egypt during the period of study (1996-2012). The study based on published and unpublished data from various issues of Agricultural Economic Bulletin Published by Ministry of Agricultural and from statistical year book published by the central agency for public mobilization and statistics, both descriptive as well as quantitative analysis have applied to analyzed collected data.

The study estimated the main features and general trends for the development of national production, consumption, annual individual consumption, food gap, foreign trade and the rate of self sufficiency for table eggs during the period of study (1996-2012).

The study indicates that the production and consumption of table eggs in Egypt was about 472 and 475 thousand tons in 2012, ad then increased to about 530.9 and 529.2 thousand tons in 2020 respectively. The study indicate that an average per capita from table eggs in Egypt was about $4.4 \mathrm{~kg}$ in 2012 , and then growing to 4.624 $\mathrm{kg}$ in 2020, Also the rate of self-sufficiency for table eggs in Egypt was about 99.4\% in 2012 , and then growing to $99.3 \%$ in 2020 .

following :

In the light of results that have been presented, the study recommended the

1- Encourage producers of table eggs to increase the capacities productivity capacity homosexual in order to raise efficiency of resource use to the maximum extent possible.

2- Encouragement of investment in table eggs production in the private and cooperative sectors in the Arab Republic of Egypt.

3- Pay attention to the productive resources used in the manufacture of table eggs for redistribution to achieve the efficiency distribution to be used.

4- Feed should be available at affordable prices throughout the year, especially in summer season.

5- The establishment of consortia from the producers of table eggs to enable them to purchase inputs and sell their products at reasonable prices so as to reduce production costs and marketing and then increase the profits of table eggs producers. 